\title{
$\begin{array}{ll}\text { Research Square } & \text { Preprints are preliminary reports that have not undergone peer review. } \\ \text { They should not be considered conclusive, used to inform clinical practice, } & \text { or referenced by the media as validated information. }\end{array}$
}

\section{Bioinformatics Analysis of the Expression and Role of microRNA-221-3p in the Head and Neck Squamous Cell Carcinoma}

\section{Ziyan Zhou}

Guangxi Medical University First Affiliated Hospital,Guangxi Tumor Radiation Therapy Clinical Medical Research Center

\section{Wenling Wu}

Guangxi Medical University First Affiliated Hospital

Jixi Li

Guangxi Medical University Firth Affiliated Hospital; Guangxi Tumor Radiation Therapy Clinical Medical Research Center

\section{Chang Liu}

Guangxi Medical University

\section{Zixi Xiao}

Guangxi Medical University

\section{Qinqiao Lai}

Guangxi Medical University

\section{Rongxing Qin}

Guangxi Medical University

\section{Mingjun Shen}

Guangxi Medical University First Affiliated Hospital;Guangxi Tumor Radiation Therapy Clinical Medical Research Center

\section{Shuo Shi}

Guangxi Medical University First Affiliated Hospital

min kang ( $\square$ kangmin@gxmu.edu.cn )

The First Affiliated Hospital of Guangxi Medical University

\section{Research article}

Keywords: HNSCC, miR-221-3p, RT-qPCR, TCGA, bioinformatics

Posted Date: December 31st, 2020

DOI: https://doi.org/10.21203/rs.3.rs-136851/v1 
License: (c) (i) This work is licensed under a Creative Commons Attribution 4.0 International License. Read Full License

Version of Record: A version of this preprint was published at BMC Cancer on April 12th, 2021. See the published version at https://doi.org/10.1186/s12885-021-08039-5. 


\section{Abstract}

\section{Background}

Head and neck squamous cell carcinoma (HNSCC) is the sixth most common cancer subtype globally, associated with a high rate of morbidity and mortality. However, the target genes of miR-221-3p and the underlying mechanism involved in HNSCC were not known. Therefore, in the current study, we studied the role of miR-221-3p in the HNSCC.

\section{Methods}

Tissues collected from 48 control and 21 HNSCC patients were processed to check the differential expression of miR-221-3p by RT-qPCR. Overexpression of microRNA-221-3p (miR-221-3p) is significantly correlated to the onset and progression of HNSCC. We also conducted the meta-analysis of the cancer literature from the cancer genome atlas (TCGA) and the Gene Expression Omnibus (GEO) database to estimate the expression of miR-221-3p in HNSCC. The miR-221-3p target genes in the HNSCC were predicted with the miRWalk and TCGA databases, and functionally annotated via the Gene Ontology Finally, Spearman's analysis was used to determine the role of the related target genes in important pathways involved in the development of HNSCC.

\section{Results}

We observed a significantly higher expression of miR-221-3p in HNSCC compared to the normal with a summary receiver operating characteristic (sROC) of $0.86(95 \% \mathrm{Cl}: 0.83,0.89)$. The KEGG and GO comprehensive analysis predicted that miR-221-3p might be involved in the development of HNSCC through the following metabolic pathways, viz Drug metabolism - cytochrome P450 UGT1A7 and MAOB may be important genes for the role of mir-221-3p.

\section{Conclusions}

Our results indicate that miR-221-3p may be used as a non-invasive and hypersensitive biomarker in the diagnosis. Thus, it can be concluded that miR-221-3p is an extremely important gene locus involved in the process of the deterioration and eventual tumorigenesis of HNSCC.

\section{Background}

Head and neck squamous cell carcinoma (HNSCC)encompassing the oral squamous cell carcinoma, oropharyngeal squamous cell carcinoma, hypopharyngeal squamous cell carcinoma and laryngeal squamous cell carcinoma is the sixth most common cancer worldwide, accounting for approximately 1$2 \%$ of all cancer deaths, with about 600,000 detection of new cases each year globally[1-3].The treatment of patients at the early stage is relatively successful, but the overall survival rate of recurrent or metastatic HNSCC remains low and has barely seen any improvements in their survival for decades[4, 5]. Although the past three decades have seen several improvements in the diagnostic tools and treatment 


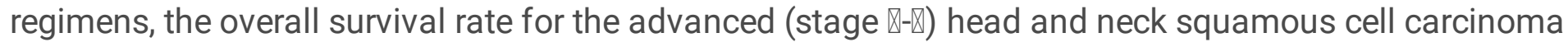
(HNSCC) is only $65 \%[6,7]$. The current standard of care for such patients are surgery along with radiation and chemotherapy, but these have not significantly improved the 5-year survival of the HNSCC patients. There is an urgent need for the e main reason for the decline in patient survival is the lack of a powerful therapeutic target for the development of HNSCC $[8,9]$.

Recent years have seen an increasing concentration of research in, microRNA (miRNA) [10, 11], which are a type of highly conserved single-stranded non-coding RNA, containing $17 \sim 22$ nucleotides and are involved in the process of tumorigenesis, cell survival, and chemosensitivity[12-14]. They bind the 3'nonregion ( $3^{\prime} U T R$ ) of different target mRNA (messenger RNA) genes to degrade or inhibit the mRNA translation of target genes associated with a tumor suppressor function[13,15, 16]. In normal healthy individuals, miR-221-3p is observed to play a role in the process of vascular proliferation[17], while the tumor promoter, microRNA-221 is involved in the process of regulation of apoptosis of the tumor cell[18$20]$ and is associated with a variety of cancer types, including hepatocellular cancer[21], cutaneous melanoma[19], prostate cancer[20],non-small cell lung cancer[22].

Studies have shown that specific miRNA profiles can be identified between tumor tissue and adjacent healthy tissue in the HNSCC patients[2, 23]. For instance, studies have reported the link between miR-211 and vascular invasion during the incidence of $\operatorname{HNSCC}[14,15,24-26]$. However, the definite target gene of the miR-211-3p and its biological mechanism of action are still not clear. Thus, in the current study, we investigated the expression of miR-221-3p in the HNSCC and attempted to explore the correlation between the two.

\section{Methods}

\section{RT -qPCR}

Tissue specimens were collected from 48 control and 21 HNSCC patients from the Department of Pathology, First Affiliated Hospital of Guangxi Medical University (Nanning, Guangxi Medical University), and processed for RT-qPCR with the SYBR-Green Master mix (Takara, Tokyo, Japan) in a ABI 7500 cycler (Applied Biosystems) with the following conditions: initial denaturation at $95^{\circ} \mathrm{C}$ for $30 \mathrm{sec}$, followed by 40 cycles of denaturation at $95^{\circ} \mathrm{C}$ for $5 \mathrm{sec}$ and annealing at $60^{\circ} \mathrm{C}$ for $34 \mathrm{sec}$. The differential expression of miR-21 in the HNSCC tissues relative to the negative control (NC) tissues was calculated using the 2- $\Delta \Delta$ Ct method, with U6 as the internal control. The primers of miR-221-3p and U6 were synthesized by TaKaRa (Dalian, Liaoning, China) and the sequences are as follows: miR-221-3p: Forward 5' AGCUACAUUGUCUGCUGGGUUUC - 3' and Reverse 5' mRQ 3'; U6: Forward 5' GGAACGATACAGAGAAGATTAGC-3' and Reverse 5' - TGGAACGCTTCACGAATTTGCG - 3'. All the experiments were repeated three times.

\section{Literature search and selection strategy.}


Literature search was conducted with the PubMed,Chinese Biomedical Literature Database (CBM)【Science Direct $\square$ the China National Knowledge Infrastructure Database (CNKI), Web of Science, Wiley online library, EMBASE, the China Science and Technology Journal Database (VIP) and the Wan fang Database for this study. We searched the database from the earliest available data beginning to October 1, 2019.The following keywords were used: (HNSCC OR SCC OR "squamous cell cancer" OR "squamous cell carcinoma") AND (oropharynx OR oropharyngeal OR "head and neck" OR nose OR nasopharynx OR "nasal sinus" OR "nasal cavity" OR "oral cavity" OR hypopharynx OR oral OR laryngopharynx OR larynx OR laryngopharyngeal OR laryngeal OR pharyngeal OR tongue OR tonsil OR tonsillar OR cheek OR palatal OR "paranasal sinuses" OR buccal OR lip) AND (microRNA-221-3p OR miRNA-221-3p OR “miR 221-3p” OR “miRNA 221-3p” OR miRNA221-3p OR miR221-3p )

\section{Selection criteria and data extraction.}

The databases were searched independently by two researchers who selected the studies based on the following inclusion criteria: (1) comparison of HNSCC and non-cancerous tissues, (2) validation of miR221-3p expression levels via reverse transcription quantitative PCR (RT-qPCR), (3) evaluation of the association between miR-221-3p expression and clinical outcomes, and (4) availability of sufficient data to calculate the mean, standard deviation (SD) and $95 \%$ confidence intervals $(95 \% \mathrm{Cl})$. The articles were eliminated if they met one of the following exclusion criteria: (1) irrelevant to the research focus, (2) inclusion of unqualified data, (3) publication language other than English or Chinese, (4) overlapping or duplicate publications, and (5) letters, reviews, comments, editorials, conference articles, laboratory studies or case reports. The reviewers independently appraised the quality of data in each eligible study and extracted the first author name, year of publication, country of origin, sample type, sample size and analysis method. For articles with incomplete information, the authors were contacted to obtain relevant information.

\section{Microarray data collection from GEO.}

Microarray data of HNSCC samples uploaded till October 1, 2019 was obtained from GEO database (https://www.ncbi.nlm.nih.gov/gds/) using the following keywords: (HNSCC OR SCC OR "squamous cell cancer" OR "squamous cell carcinoma") AND (oropharynx OR oropharyngeal OR "head and neck" OR nose OR nasopharynx OR "nasal sinus" OR "nasal cavity" OR "oral cavity" OR hypopharynx OR oral OR laryngopharynx OR larynx OR laryngopharyngeal OR laryngeal OR pharyngeal OR tonsil OR tonsillar OR tongue OR cheek OR palatal OR "paranasal sinuses" OR buccal OR lip) AND ( microRNA OR miRNA OR "miR" OR "miRNA"). The inclusion criteria for the microarray datasets were: (1) comprising of data from HNSCC and non-cancerous tissues, (2) evaluation of the association between miR-221-3p expression and clinical outcomes, (3) availability of sufficiently data to calculate mean, SD and $95 \% \mathrm{Cl}$. The exclusion criteria were: (1) unrelated to this study, (2) unqualified data, (3) publication language other than English.

\section{RNA sequencing data selection from TCGA.}


MiR-221-3p expression data of HNSCC and normal tissues, and the clinico-pathological parameters, were downloaded and extracted from the OncoLnc website (http://www.oncolnc.org/) (13). SPSS24.0 (Nanning, Guangxi Zhuang Autonomous Region, China) was used to determine the association between miR-221-3p expression levels and other factors.

\section{Statistical analysis}

Continuous variables and meta-analysis of the data of the available cancer literature, The Cancer Genome Atlas (TCGA) and GEO(Gene Expression Omnibus). The meta-analysis data was verified by PCR. Further, we used diagnostic meta-analysis to estimate the potential diagnostic value of miR-221-3p. In addition, the Kyoto Encyclopedia of Genes and Genomes (KEGG) and Gene Ontology (GO) enrichment analyses were used to comprehensively analyze the possible molecular mechanisms of miR-221-3p in HNSCC.

\section{Comprehensive statistical analysis of the data}

Data which were removed from our meta-analysis as well as TCGA data (Nanning, Guangxi Zhuang Autonomous Region, China) were analyzed using the STATA 15.0 software. Standard mean difference (SMD) and 95\% confidence interval were used to estimate the expression value of miR-221-3p. In normal and HNSCC, scatter plots prepared with the GraphPad Prism 6 (Nanning, Guangxi Zhuang Autonomous Region, China) of the data of both the normal and HNSCC tissues were used to assess the expression level of miR-221-3p. Evidence of bias was assessed by the visual funnel plots and Egger's regression asymmetry test. In addition, the $\mathrm{I}^{2}$ index was used to evaluate the potential heterogeneity of the selected data. When $\mathrm{I}^{2}>50 \%$ or $\mathrm{P}<0.05$, we used the fixed effect model; otherwise, the random effect model was used. SPSS 24.0 software (IBM, Somers, NY) was used for the statistical analysis. Mean $\pm S D(X \pm s)$ and $t$ test for comparisons between groups were applied all to the measurement data. The count rate was expressed as a percentage (\%), and we used the X2 test for comparison. Based on true positive (TP), false positive (FP), false negative (FN) and true negative (TN) to determine the diagnostic value of miR-221-3p, we used the meta-disc software to calculate the specificity, sensitivity, likelihood ratio (negative and positive) receiver operating characteristic curve (SROC). We also did the sensitivity analysis to assess the differences between the sample sizes. Moreover, all the miR-221-3p expression data which included the TCGA sequence was normalized to log2 to improve the normality of the measurements. $P<0.05$ is considered a statistically significant value.

\section{Predicting target genes of mir-221 in HNSCC}

The Gene Ontology (GO)[27]analysis was used to define biological processes (BP), molecular function (MF), and cellular components (CC), and the Kyoto Encyclopedia of Genes and Genomes (KEGG)[28] pathway enrichment analyses were conducted using $R$ (version 3.6.1) to visualize the ClusterProfiler of $R$. The Search Tool for the Retrieval of Interacting Genes (STRING) (https://string-db.org/) was then used to establish a protein-protein interaction (PPI) network of the miR-221-3p target genes associated with the significantly enriched pathways. The expression levels of the miR-221-3p target genes in the HNSCC and non-tumor tissues were determined with the UALCOULD[29] (http://ualcan.path.uab.edu/index.html). 
Finally, the Linkedomics[30] (http://www.linkedomics.org/) Spearman's analysis tool was applied to determine the correlation between the expression levels of the miR-221-3p and the potential target genes involved in notable signaling pathways.

\section{Result}

\section{miR-221-3p is highly expressed in the tumor tissues}

The RT-qPCR data clearly showed that miR-221-3p is highly expressed in the tissues of the nasopharyngeal carcinoma patients as compared to the control group $(p<0.05)($ Fig. 1).

Selection of relevant literature and microarray data extraction.

A total of 17 articles were retrieved from the initial search, and the following paper was selected after the full-text review based on the inclusion criteria (Fig. 2): Zhou Cheng. et al (PMID: 30928631)[31]. Sixteen out of 424 GEO microarray datasets - GSE11163, GSE103931, GSE107591, GSE113956, GSE28100, GSE31277, GSE34496, GSE45238, GSE51829, GSE58911, GSE69002, GSE70289, GSE73171, GSE75630, GSE82064, GSE98463 - met our inclusion criteria. The information is summarized in Table 1. 
Table 1

The main features of included studies for this meta-analysis

\begin{tabular}{|llllll|}
\hline Researcher & Year & Country & Cancer/normal & Methods & Sample \\
\hline TCGA & 2019 & USA & $523 / 44$ & qPCR & Tissue \\
\hline GSE11163 & 2012 & USA & $16 / 5$ & qPCR & Tissue \\
\hline GSE103931 & 2018 & Taiwan & $30 / 19$ & qPCR & Tissue \\
\hline GSE107591 & 2018 & USA & $24 / 23$ & qPCR & Tissue \\
\hline GSE113956 & 2019 & China & $25 / 15$ & qPCR & Tissue \\
\hline GSE28100 & 2015 & USA & $17 / 3$ & qPCR & Tissue \\
\hline GSE31277 & 2018 & Brazil & $15 / 15$ & qPCR & Tissue \\
\hline GSE34496 & 2017 & USA & $44 / 25$ & qPCR & Tissue \\
\hline GSE45238 & 2019 & USA & $40 / 40$ & qPCR & Tissue \\
\hline GSE51829 & 2013 & China & $4 / 4$ & qPCR & Tissue \\
\hline GSE58911 & 2018 & USA & $15 / 15$ & qPCR & Tissue \\
\hline GSE69002 & 2017 & USA & $3 / 4$ & qPCR & Tissue \\
\hline GSE70289 & 2018 & USA & $12 / 4$ & qPCR & Tissue \\
\hline GSE73171 & 2017 & Hong Kong & $3 / 3$ & qPCR & Tissue \\
\hline GSE75630 & 2016 & Australia & $28 / 18$ & qPCR & Tissue \\
\hline GSE82064 & 2017 & Switzerland & $78 / 18$ & qPCR & Tissue \\
\hline GSE98463 & 2018 & Spain & $8 / 8$ & qPCR & Tissue \\
\hline Zhou Cheng. et al & 2019 & China & $26 / 26$ & qPCR & Tissue \\
\hline
\end{tabular}

\section{Bias risk assessment}

The results of the visual funnel plots show a symmetrical shape, which indicate absence of any significant publication bias as a whole. Sensitivity analysis performed on the heterogeneity samples showed that there did not exist any significant difference between the studies (Fig. 3).

Expression and meta-analysis of miR-221-3p in the HNSCC From the total of 911 HNSCC samples and 289 normal samples of the Pubmed, GEO and TGCA datasets, we observed that miR-221-3p is overexpressed in the HNSCC compared to the normal tissues $(P<0.05)$. Which is consistent with the results obtained by RT-qPCR. Meta-analysis to explore the level of expression of mrR-221-3p in HNSCC indicate a high degree of heterogeneity between these studies. Therefore, the random-effect mode was selected and the combined standard deviation (SMD) was observed to be $0.717(95 \% \mathrm{Cl}: 0.283,1.152)$ 
(Fig. 4). The meta-analysis data indicate that miR-221-3p expression is significantly upregulated in the HNSCC. In addition, the expression levels of mir-221-3p in HNSCC and normal tissues from each included dataset is shown in Fig. 5 (A-R).

\section{Diagnostic value of miR-221-3p in HNSCC}

The random-effects mode applied to analyze the diagnostic value of miR-221-3p for HNSCC showed a significant heterogeneity in the likelihood ratios (negative and positive) sensitivity and specificity analyses. Diagnostic meta-analysis results indicated that mixed specificity, sensitivity, likelihood ratio (negative and positive) and diagnostic odds ratio to be $0.78(95 \% \mathrm{Cl}: 0.72-0.82), 0.57(95 \% \mathrm{Cl}: 0.54-0.60)$, $0.42(95 \% \mathrm{Cl}: 0.31-0.56)$ and 3.04(95\% Cl:1.72-5.40) respectively (Fig. 6). The ROC curve is shown in Fig. 7. Based on the ROC of each study, the total ROC curve indicated that the area under the sROC curve (AUC) analysis is $0.86(95 \% \mathrm{Cl}: 0.83,0.89)$ (Fig. 8).

\section{Clinical -pathological features of HNSCC based on the TCGA}

Based on the sample data of the HNSCC extracted from the TCGA database, we analyzed 527 samples, which indicate the absence of any statistically significant difference between miR-221-3p expression and age, lymphovascular invasion,Neoplasm histologic grade or any other clinical-pathological features. However, it indicated a statistically significant difference in the expression of miR-221-3p that mainly refer to the different tissue, gender and clinical stage, even alcohol. (Table 2). 
Table 2

The correlation between miR-221-3p expression levels and clinic characteristics based on TCGA database

\begin{tabular}{|c|c|c|c|c|}
\hline Clinicopathological features & Terms & $\mathrm{n}$ & Mean \pm SD & p-value \\
\hline \multirow[t]{2}{*}{ Unpaired tissue } & Normal & 44 & $8.16 \pm 0.64$ & 0.001 \\
\hline & HNSCC & 480 & $8.55 \pm 0.78$ & \\
\hline \multirow[t]{2}{*}{ Gender } & Male & 383 & $8.45 \pm 0.79$ & 0.001 \\
\hline & Female & 141 & $8.71 \pm 0.68$ & \\
\hline \multirow[t]{2}{*}{ Age } & $<60$ & 234 & $8.50 \pm 0.76$ & 0.559 \\
\hline & $>=60$ & 290 & $8.54 \pm 0.78$ & \\
\hline \multirow[t]{2}{*}{ lymphovascular invasion } & NO & 232 & $8.54 \pm 0.81$ & 0.429 \\
\hline & YES & 292 & $8.49 \pm 0.75$ & \\
\hline \multirow[t]{2}{*}{ Clinical stage } & $1-7$ & 206 & $8.63 \pm 0.76$ & 0.011 \\
\hline & $\mathbb{Q}-\mathbb{\square}$ & 318 & $8.45 \pm 0.78$ & \\
\hline \multirow[t]{2}{*}{ Neoplasm histologic grade } & G1-G2 & 371 & $8.49 \pm 0.73$ & 0.260 \\
\hline & G3-G4 & 156 & $8.58 \pm 0.82$ & \\
\hline \multirow[t]{2}{*}{ T stage } & T1-T2 & 188 & $8.61 \pm 0.73$ & 0.029 \\
\hline & T3-T4 & 336 & $8.46 \pm 0.79$ & \\
\hline \multirow[t]{2}{*}{ M stage } & MO & 498 & $8.51 \pm 0.78$ & 0.967 \\
\hline & M1 & 29 & $8.51 \pm 0.57$ & \\
\hline \multirow[t]{2}{*}{ N stage } & NO & 246 & $8.53 \pm 0.76$ & 0.572 \\
\hline & N1-N3 & 281 & $8.49 \pm 0.77$ & \\
\hline Alcohol & NO & 164 & $8.62 \pm 0.76$ & 0.047 \\
\hline \multirow[t]{3}{*}{ HPV status } & YES & 363 & $8.48 \pm 0.76$ & 0.066 \\
\hline & Negative & 194 & $8.41 \pm 0.81$ & \\
\hline & Positive & 330 & $8.55 \pm 0.81$ & \\
\hline \multirow[t]{2}{*}{ Perineural invasion } & NO & 198 & $8.53 \pm 0.81$ & 0.693 \\
\hline & YES & 329 & $8.50 \pm 0.80$ & \\
\hline
\end{tabular}

Notes: HNSCC, Head and neck squamous cell carcinoma; T stage, size or direct extent of the primary tumor; $\mathrm{N}$ stage, degree of spread to regional lymph nodes; M stage, presence of distant metastasis; $\mathrm{SD}$, standard deviation 


\begin{tabular}{|lllll|}
\hline Clinicopathological features & Terms & $\mathbf{n}$ & Mean \pm SD & p-value \\
\hline Smoking & $<3$ & 298 & $8.47 \pm 0.76$ & 0.094 \\
& $\geq 3$ & 229 & $8.58 \pm 0.77$ & \\
\hline
\end{tabular}

Notes: HNSCC, Head and neck squamous cell carcinoma; T stage, size or direct extent of the primary tumor; $\mathrm{N}$ stage, degree of spread to regional lymph nodes; M stage, presence of distant metastasis; $\mathrm{SD}$, standard deviation

\section{The prospective target genes of miR-221 in HNSCC}

By using MiRWalk2.0[32] (http://zmf.umm.uni-heidelberg.de/apps/zmf/mirwalk2/), and GEPIA(http://gepia.cancer-pku.cn/index.html) analysis, we retrieved the number of the differentially expressed genes to be 5311 and 467respectively. Bioinformatics analysis showed a total of 117 overlap genes which were involved, as shown in Fig. 9 and Table 3. The enriched GO and KEGG pathway category overlapping genes with $p<0.05$ are shown in Fig. 10, Table 4 and Table5. For the cellular component,the identified target genes are mostly enriched in the actin cytoskeleton, sarcomere, contractile fiber part $\square$ and the molecular function is mainly concerned with the aromatase activity, oxidoreductase activity, and cofactor binding. KEGG enrichment analysis showed that miR-221-3p plays a significant role in HNSCC through a variety of pathways, including the drug metabolism pathways of the cytochrome P450 signaling pathway. The protein-protein interaction (PPI) network of drug metabolism - cytochrome P450related genes is shown in the Fig. 11.

Table 3

The promising target genes of miR-221-3p in HNSCC with TCGA and MiRWalk

Sources Genes
of genes

TCGA $\quad$ AADAC $₫ A C P P \square A D H 1 B \square A D H 1 C \square A L D H 1 A 1 \square A M O T \square A N K R D 35 \square A N X A 1 \square A Q P 3 \square A S B 5 \square A T P 2 A 1$ and MiRWalk

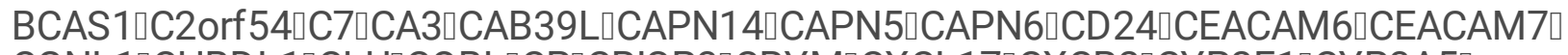

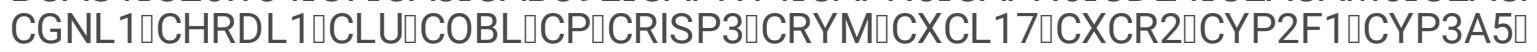
CYP4B1

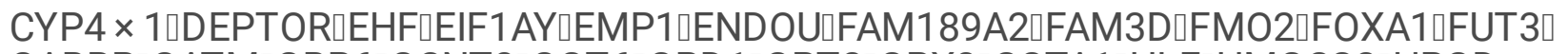
GABRP $\square A T M \square G B P 6 \square G C N T 3 \square G G T 6 \square G P D 1 \square G P T 2 \square G P X 3 \square G S T A 1 \square H L F \square H M G C S 2 \square H P G D$

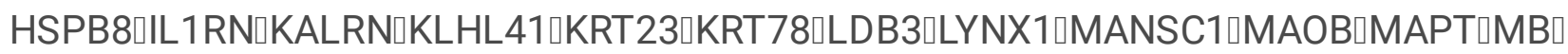

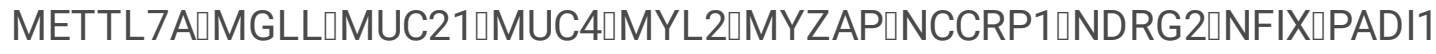

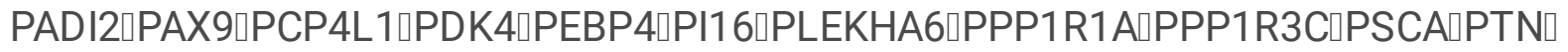

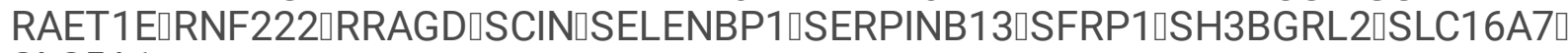
SLC5A1

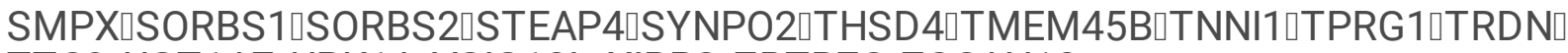

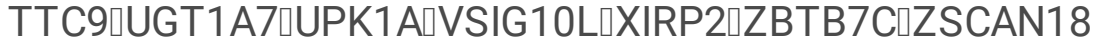

Notes:HNSCC: Head and neck squamous cell carcinoma; TCGA: The Cancer Genome Atlas. 
Table 4

Predictive target genes of miR-221-3p with GO analysis

\begin{tabular}{|c|c|c|c|c|}
\hline GO ID & GO term & $\begin{array}{l}\text { Count } \\
(\%)\end{array}$ & Gene symbol & $\begin{array}{l}P \\
\text { value }\end{array}$ \\
\hline \multicolumn{5}{|l|}{$\begin{array}{l}\text { Cellular } \\
\text { component }\end{array}$} \\
\hline GO:0015629 & actin cytoskeleton & 12 & 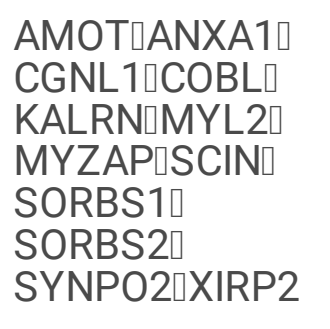 & $\begin{array}{l}6.22 \mathrm{E}- \\
06\end{array}$ \\
\hline GO:0030017 & sarcomere & 7 & 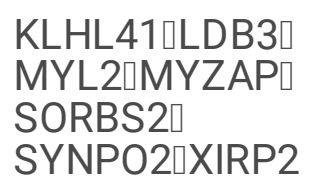 & $\begin{array}{l}6.06 \mathrm{E}- \\
05\end{array}$ \\
\hline G0:0044449 & contractile fiber part & 7 & 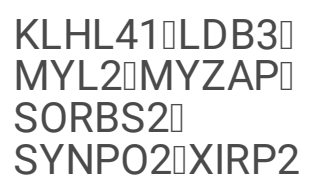 & $\begin{array}{l}1.12 \mathrm{E}- \\
04\end{array}$ \\
\hline G0:0030016 & myofibril & 7 & 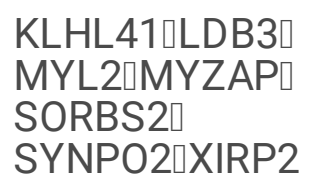 & $\begin{array}{l}1.32 \mathrm{E}- \\
04\end{array}$ \\
\hline GO:0043292 & contractile fiber & 7 & 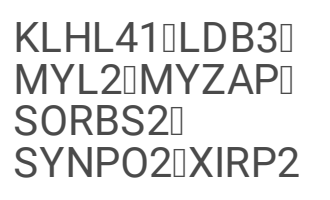 & $\begin{array}{l}1.90 \mathrm{E}- \\
04\end{array}$ \\
\hline G0:0030018 & Z disc & 5 & 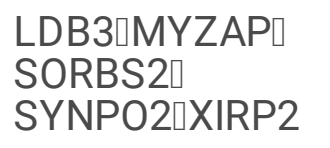 & $\begin{array}{l}3.44 \mathrm{E}- \\
04\end{array}$ \\
\hline GO:0031674 & I band & 5 & 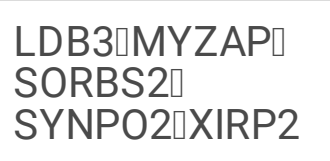 & $\begin{array}{l}5.21 \mathrm{E}- \\
04\end{array}$ \\
\hline G0:0033017 & sarcoplasmic reticulum membrane & 3 & $\begin{array}{l}\text { ATP2A1口 } \\
\text { KLHL410TRDN }\end{array}$ & $\begin{array}{l}1.11 \mathrm{E}- \\
03\end{array}$ \\
\hline \multicolumn{5}{|l|}{$\begin{array}{l}\text { Molecular } \\
\text { function }\end{array}$} \\
\hline G0:0070330 & aromatase activity & 4 & $\begin{array}{l}\text { CYP2F10 } \\
\text { CYP3A50 } \\
\text { CYP4B10CYP4 × } \\
1\end{array}$ & $\begin{array}{l}6.04 \mathrm{E}- \\
06\end{array}$ \\
\hline
\end{tabular}

Notes: GO: Gene Ontology 


\begin{tabular}{|c|c|c|c|c|}
\hline GO ID & GO term & $\begin{array}{l}\text { Count } \\
(\%)\end{array}$ & Gene symbol & $\begin{array}{l}P \\
\text { value }\end{array}$ \\
\hline GO:0016712 & $\begin{array}{l}\text { oxidoreductase activity, acting on paired } \\
\text { donors, with incorporation or reduction of } \\
\text { molecular oxygen, reduced flavin or } \\
\text { flavoprotein as one donor, and incorporation } \\
\text { of one atom of oxygen }\end{array}$ & 4 & $\begin{array}{l}\text { CYP2F10 } \\
\text { CYP3A5 } \\
\text { CYP4B10CYP4 } \\
1\end{array}$ & $\begin{array}{l}8.86 \mathrm{E}- \\
06\end{array}$ \\
\hline GO:0048037 & cofactor binding & 12 & 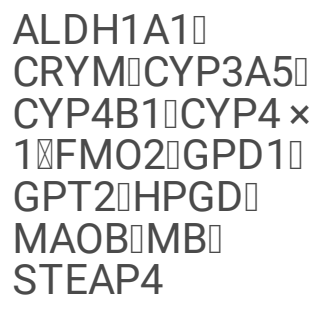 & $\begin{array}{l}9.13 \mathrm{E}- \\
06\end{array}$ \\
\hline GO:0019825 & oxygen binding & 4 & $\begin{array}{l}\text { CYP2F1" } \\
\text { CYP3A5! } \\
\text { CYP4B1IMB }\end{array}$ & $\begin{array}{l}1.73 \mathrm{E}- \\
05\end{array}$ \\
\hline G0:0050662 & coenzyme binding & 8 & 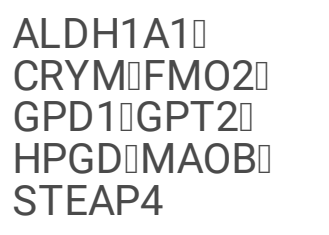 & $\begin{array}{l}1.30 \mathrm{E}- \\
04\end{array}$ \\
\hline GO:0004497 & monooxygenase activity & 5 & $\begin{array}{l}\text { CYP2F10 } \\
\text { CYP3A5 } \\
\text { CYP4B10CYP4× } \\
\text { 1هFM02 }\end{array}$ & $\begin{array}{l}1.46 \mathrm{E}- \\
04\end{array}$ \\
\hline G0:0051393 & alpha-actinin binding & 3 & $\begin{array}{l}\text { LDB3ロSYNPO2』 } \\
\text { XIRP2 }\end{array}$ & $\begin{array}{l}2.37 \mathrm{E}- \\
04\end{array}$ \\
\hline G0:0020037 & heme binding & 5 & 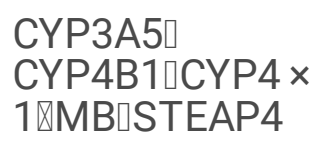 & $\begin{array}{l}3.88 \mathrm{E}- \\
04\end{array}$ \\
\hline G0:0046906 & tetrapyrrole binding & 5 & 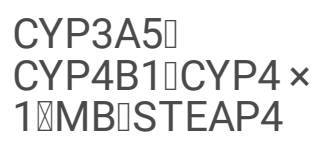 & $\begin{array}{l}5.87 \mathrm{E}- \\
04\end{array}$ \\
\hline G0:0042805 & actinin binding & 3 & $\begin{array}{l}\text { LDB3[SYNPO2』 } \\
\text { XIRP2 }\end{array}$ & $\begin{array}{l}6.30 \mathrm{E}- \\
04\end{array}$ \\
\hline GO:0016705 & $\begin{array}{l}\text { oxidoreductase activity, acting on paired } \\
\text { donors, with incorporation or reduction of } \\
\text { molecular oxygen }\end{array}$ & 5 & $\begin{array}{l}\text { CYP2F10 } \\
\text { CYP3A50 } \\
\text { CYP4B10CYP4× } \\
\text { 1هFM02 }\end{array}$ & $\begin{array}{l}1.24 \mathrm{E}- \\
03\end{array}$ \\
\hline G0:0033130 & acetylcholine receptor binding & 2 & LYNX1IPSCA & $\begin{array}{l}1.47 \mathrm{E}- \\
03\end{array}$ \\
\hline
\end{tabular}

Notes: GO: Gene Ontology 


\begin{tabular}{|c|c|c|c|c|}
\hline GO ID & GO term & $\begin{array}{l}\text { Count } \\
(\%)\end{array}$ & Gene symbol & $\begin{array}{l}P \\
\text { value }\end{array}$ \\
\hline GO:0016722 & oxidoreductase activity, oxidizing metal ions & 2 & CPISTEAP4 & $\begin{array}{l}2.14 \mathrm{E}- \\
03\end{array}$ \\
\hline GO:0030674 & protein binding, bridging & 5 & 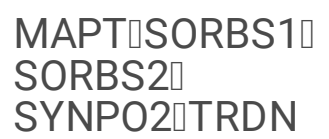 & $\begin{array}{l}2.20 \mathrm{E}- \\
03\end{array}$ \\
\hline
\end{tabular}

Table 5

KEGG pathway of validated target genes of miR-221-3p

\begin{tabular}{|c|c|c|c|c|}
\hline KEGG ID & KEGG term & $\begin{array}{l}\text { Count } \\
\text { (\%) }\end{array}$ & Gene symbol & $p-$ \\
\hline hsa00982 & $\begin{array}{l}\text { Drug metabolism - cytochrome } \\
\text { P450 }\end{array}$ & 7 & $\begin{array}{l}\text { GSTA1, UGT1A7, CYP3A5, FMO2, } \\
\text { MAOB, ADH1C, ADH1B }\end{array}$ & $\begin{array}{l}3.18 \mathrm{E}- \\
07\end{array}$ \\
\hline hsa00980 & $\begin{array}{l}\text { Metabolism of xenobiotics by } \\
\text { cytochrome P450 }\end{array}$ & 6 & $\begin{array}{l}\text { GSTA1, UGT1A7, CYP3A5, } \\
\text { CYP2F1, ADH1C, ADH1B }\end{array}$ & $\begin{array}{l}8.10 \mathrm{E}- \\
06\end{array}$ \\
\hline hsa00830 & Retinol metabolism & 5 & $\begin{array}{l}\text { UGT1A7, ALDH1A1, CYP3A5, } \\
\text { ADH1C, ADH1B }\end{array}$ & $\begin{array}{l}6.43 \mathrm{E}- \\
05\end{array}$ \\
\hline hsa05204 & Chemical carcinogenesis & 5 & $\begin{array}{l}\text { GSTA1, UGT1A7, CYP3A5, ADH1C, } \\
\text { ADH1B }\end{array}$ & $\begin{array}{l}1.69 \mathrm{E}- \\
04\end{array}$ \\
\hline hsa00350 & Tyrosine metabolism & 3 & $\mathrm{MAOB}, \mathrm{ADH} 1 \mathrm{C}, \mathrm{ADH} 1 \mathrm{~B}$ & $\begin{array}{l}1.54 \mathrm{E}- \\
03\end{array}$ \\
\hline \multicolumn{5}{|c|}{ Notes: KEGG: Kyoto Encyclopedia of Genes and Genomes } \\
\hline
\end{tabular}

Seven target genes associated with miR-221-3p are also involved in the drug metabolism - cytochrome P450 pathway and are down-regulated. The expression value of each of the target genes are shown in Fig. 12. The Spearman's correlation analysis showed that the correlation of the certified target genes with miR-221-3p in HNSCC (Fig. 13).

\section{Discussion}

The Drug metabolism - cytochrome P450 signaling pathway is an essential signal transduction pathway in cells. It is an important biological function of cell survival, proliferation and apoptosis. For example, Liping Wang and his colleagues suggest[33] that inhibition of CYP3A5 in the cytochrome P450 Drug metabolism can drive the migration, proliferation, and invasion of HNSCC cells. Dongfang Wang.et al 
show that the cytochrome P450 is correlated with the overall survival and vascular invasion of Hepatocellular carcinoma (HCC) patients. Additionally, inhibiting the P450 pathway on drug metabolism cytochrome can increase the efficacy of the HNSCC[34]. In the target genes of mir-221-3p, MAOB and UGT1A7 is associated with the mir-221-3p and drug-cytochrome P450 signaling pathways, are downregulated in the HNSCC $(P<0.05)$. MAOB is regarded as novel biomarkers for accurate Prostate cancer diagnosis and treatment[35]. In addition, a large number of valuable epidemiological studies have shown that UGT1A7 affects individuals' susceptibility to various cancers, such as pancreatic cancer[36],gastrointestinal carcinomas[37].Now our study suggests that miR-221-3p may play an important role

as a gene that promotes the development of HNSCC, by reducing the expression of MAOB and UGT1A7 pathways in HNSCC.Of course, our study has some limitations. The target gene of mir-221-3p have not been experimentally confirmed and we believe that our conclusions will need to be confirmed by clinical or molecular biological methods in the nearly future.

Understanding the pathogenesis of HNSCC and identifying new gene therapy programs are the focus of recent studies. Many recent studies have reported that the miRNAs with different expression patterns in different tumors[38-42], a control the progression of the tumors. For example, miR-221-3p has be regarded as a tumor biomarker that can be used to assess the clinical prognosis of breast cancer[15]. In healthy humans, it has been shown that miR-221-3p plays a role in the process of vascular proliferation, while the tumor promoter, miR-221-3p regulates the apoptosis of tumor cells. Now, the current study focused on the expression pattern of miR-221-3p in HNSCC, identifying the exact target gene of this miRNA and its biological mechanism of action.

In our study, we found that miR-221-3p levels were apparently up-regulated in HNSCC compared to normal tissues, also provided insights into its potential molecular mechanisms in driving cancer progression. MAOB and UGT1A7 are potentially important targets of miR-221-3p. MiR-221-3p may can be used as a non-invasive and hypersensitive biomarker in the diagnosis and is an extremely important gene locus involved in the process of the deterioration and eventual tumorigenesis of HNSCC.

\section{Abbreviations}

HNSCC: Head and neck squamous cell carcinoma; miR: microRNA; PPI: protein-protein interaction; GO: Gene Ontology; KEGG, Kyoto Encyclopedia of Genes and Genomes; GEO: Gene Expression Omnibus; TCGA: The cancer genome atlas; DAVID: Database for Annotation, Visualization and Integrated Discovery; BiNGO: Biological Networks Gene Oncology tool; BP: biological process; CC: cellular component; MF: molecular function.

\section{Declarations}

\section{Ethics approval and consent to participate}


All procedures were approved by the Ethics Committee of Guangxi Medical University (Nanning, China). Written informed consent was obtained from all patients or their families prior to enrolment in the present study.

\section{Consent for publication}

Not applicable.

\section{Competing interests}

The authors declared that they have no competing interests.

\section{Funding}

This work was supported by grants from the National Natural Science Foundation of China (No. 81460460,81760542), The Research Foundation of the Science and Technology Department of Guangxi Province, China (grant No. 2016GXNSFAA380252, 2018AB61001 and 2014GXNSFBA118114), the Research Foundation of the Health Department of Guangxi Province, China (No. S2018087). The funding body had no role in the design of the study and collection, analysis, and interpretation of data and in writing this manuscript.

\section{Authors' contributions}

MK designed the study and accessed the relevant information, and ZZ and LWW collected and analyzed the data. XJL, XZX and CL were involved in statistical analysis. QQL, JMS, XRQ and SS critically revised the manuscript. All authors read and approved the final manuscript.

\section{Acknowledgements}

Not applicable.

\section{Availability of data and materials}

All data generated or analyzed during this study are included in this published article.

\section{References}

1. Avissar M, Christensen BC, Kelsey KT, Marsit CJ. MicroRNA expression ratio is predictive of head and neck squamous cell carcinoma. Clin Cancer Res. 2009;15(8):2850-5.

2. Allen B, Schneider A, Victoria B, Nunez Lopez YO, Muller M, Szewczyk M, Pazdrowski J, Majchrzak E, Barczak W, Golusinski W, et al. Blood Serum From Head and Neck Squamous Cell Carcinoma Patients Induces Altered MicroRNA and Target Gene Expression Profile in Treated Cells. Frontiers in oncology. 2018;8(undefined):217. 
3. Peitzsch C, Nathansen J, Schniewind SI, Schwarz F, Dubrovska A. Cancer Stem Cells in Head and Neck Squamous Cell Carcinoma: Identification, Characterization and Clinical Implications. Cancers. 2019;11(5):616.

4. Ausoni S, Boscolo-Rizzo P, Singh B, Da Mosto MC, Spinato G, Tirelli G, Spinato R, Azzarello G. Targeting cellular and molecular drivers of head and neck squamous cell carcinoma: current options and emerging perspectives. Cancer Metastasis Rev. 2016;35(3):413-26.

5. Britt EL, Raman S, Leek K, Sheehy CH, Kim SW, Harada H. Combination of fenretinide and ABT-263 induces apoptosis through NOXA for head and neck squamous cell carcinoma treatment. PLos One. 2019;14(7):e0219398.

6. Koole K, Clausen MJ, van Es RJ, van Kempen PM, Melchers LJ, Koole R, Langendijk JA, van Diest PJ, Roodenburg JL, Schuuring E, et al. FGFR Family Members Protein Expression as Prognostic Markers in Oral Cavity and Oropharyngeal Squamous Cell Carcinoma. Molecular diagnosis therapy. 2016;20(4):363-74.

7. Tang XX, He J, Li B, Zheng Y, Li KJ, Zou S, Chen L. Efficacy and Safety of Gefitinib in Patients with Advanced Head and Neck Squamous Cell Carcinoma: A Meta-Analysis of Randomized Controlled Trials. Journal of oncology 2019, 2019(undefined): 6273438.

8. Cao W, Liu J, Xia R, Lin L, Wang X, Xiao M, Zhang C, Li J, Ji T, Chen W. X-linked FHL1 as a novel therapeutic target for head and neck squamous cell carcinoma. Oncotarget. 2016;7(12):14537-50.

9. Ahmad P, Sana J, Slavik M, Slampa P, Smilek P, Slaby O. MicroRNAs Involvement in Radioresistance of Head and Neck Cancer. Dis Markers. 2017;2017:8245345.

10. Orosz E, Gombos K, Riedling T, Afiakurue P, Kiss I, Pytel J, Gerlinger I, Szanyi I. Comparative miRNA Expression Profile Analysis of Squamous Cell Carcinoma and Peritumoral Mucosa from the Mesoand Hypopharynx. Cancer Genomics Proteomics. 2017;14(4):285-92.

11. Qureshi R, Sacan A. A novel method for the normalization of microRNA RT-PCR data. BMC Med Genom. 2013;6(Suppl 1):14.

12. Irani S. miRNAs Signature in Head and Neck Squamous Cell Carcinoma Metastasis: A Literature Review. Journal of dentistry. 2016;17(2):13.

13. Wang $H$, Tang $Y$, Yang D, Zheng L. MicroRNA-591 Functions as a Tumor Suppressor in Hepatocellular Carcinoma by Lowering Drug Resistance through Inhibition of Far-Upstream Element-Binding Protein 2-Mediated Phosphoinositide 3-Kinase/Akt/Mammalian Target of Rapamycin Axis. Pharmacology 2019:1-14.

14. Hussein S, Mosaad H, Rashed HE, El-Anwar MW. Up-regulated miR-221 expression as a molecular diagnostic marker in laryngeal squamous cell carcinoma and its correlation with Apaf-1 expression. Cancer Biomark. 2017;19(3):279-87.

15. Zhou L, Jiang F, Chen X, Liu Z, Ouyang Y, Zhao W, Yu D. Downregulation of miR-221/222 by a microRNA sponge promotes apoptosis in oral squamous cell carcinoma cells through upregulation of PTEN. Oncol Lett. 2016;12(6):4419-26. 
16. Deng X, Ma L, Wu M, Zhang G, Jin C, Guo Y, Liu R. miR-124 radiosensitizes human glioma cells by targeting CDK4. J Neurooncol. 2013;114(3):263-74.

17. Rippe C, Blimline M, Magerko KA, Lawson BR, LaRocca TJ, Donato AJ, Seals DR. MicroRNA changes in human arterial endothelial cells with senescence: relation to apoptosis, eNOS and inflammation. Exp Gerontol. 2012;47(1):45-51.

18. Gillies JK, Lorimer IA. Regulation of p27Kip1 by miRNA 221/222 in glioblastoma. Cell Cycle. 2007;6(16):2005-9.

19. Felicetti F, Errico MC, Bottero L, Segnalini P, Stoppacciaro A, Biffoni M, Felli N, Mattia G, Petrini M, Colombo MP, et al. The promyelocytic leukemia zinc finger-microRNA-221/-222 pathway controls melanoma progression through multiple oncogenic mechanisms. Cancer Res. 2008;68(8):2745-54.

20. Ambs S, Prueitt RL, Yi M, Hudson RS, Howe TM, Petrocca F, Wallace TA, Liu CG, Volinia S, Calin GA, et al. Genomic profiling of microRNA and messenger RNA reveals deregulated microRNA expression in prostate cancer. Cancer Res. 2008;68(15):6162-70.

21. Li J, Wang Y, Yu W, Chen J, Luo J. Expression of serum miR-221 in human hepatocellular carcinoma and its prognostic significance. Biochem Biophys Res Commun. 2011;406(1):70-3.

22. Ergun S, Arman K, Temiz E, Bozgeyik I, Yumrutas O, Safdar M, Dagli H, Arslan A, Oztuzcu S. Expression patterns of miR-221 and its target Caspase-3 in different cancer cell lines. Mol Biol Rep. 2014;41(9):5877-81.

23. Wald Al, Hoskins EE, Wells SI, Ferris RL, Khan SA. Alteration of microRNA profiles in squamous cell carcinoma of the head and neck cell lines by human papillomavirus. Head Neck. 2011;33(4):504-12.

24. Yang CJ, Shen WG, Liu CJ, Chen YW, Lu HH, Tsai MM, Lin SC. miR-221 and miR-222 expression increased the growth and tumorigenesis of oral carcinoma cells. J Oral Pathol Med. 2011;40(7):5606.

25. Liu CJ, Kao SY, Tu HF, Tsai MM, Chang KW, Lin SC. Increase of microRNA miR-31 level in plasma could be a potential marker of oral cancer. Oral Dis. 2010;16(4):360-4.

26. Wong TS, Liu XB, Wong BY, Ng RW, Yuen AP, Wei WI. Mature miR-184 as Potential Oncogenic microRNA of Squamous Cell Carcinoma of Tongue. Clin Cancer Res. 2008;14(9):2588-92.

27. Ashburner M, Ball CA, Blake JA, Botstein D, Butler H, Cherry JM, Davis AP, Dolinski K, Dwight SS, Eppig JT, et al. Gene ontology: tool for the unification of biology. The Gene Ontology Consortium Nature genetics. 2000;25(1):25-9.

28. Kanehisa M, Goto S, Sato Y, Furumichi M, Tanabe M. KEGG for integration and interpretation of largescale molecular data sets. Nucleic acids research. 2012;40(Database issue):D109-14.

29. Chandrashekar DS, Bashel B, Balasubramanya SAH, Creighton CJ, Ponce-Rodriguez I, Chakravarthi B, Varambally S. UALCAN: A Portal for Facilitating Tumor Subgroup Gene Expression and Survival Analyses. Neoplasia (New York NY). 2017;19(8):649-58.

30. Vasaikar SV, Straub P, Wang J, Zhang B. LinkedOmics: analyzing multi-omics data within and across 32 cancer types. Nucleic acids research. 2018;46(D1):D956-d963. 
31. Cheng Z, Xing D. Ginsenoside Rg3 inhibits growth and epithelial-mesenchymal transition of human oral squamous carcinoma cells by down-regulating miR-221. Eur J Pharmacol. 2019;853:353-63.

32. Dweep H, Gretz N. miRWalk2.0: a comprehensive atlas of microRNA-target interactions. Nat Methods. 2015;12(8):697.

33. Wang LP, Chen WH, Zha J, Yan YY, Wei YX, Chen XL, Zhu XX, Ge LH. miR543 acts as a novel oncogene in oral squamous cell carcinoma by targeting CYP3A5. Oncol Rep. 2019;42(3):973-90.

34. Ruwali M, Dhawan A, Pant MC, Rahman Q, Khurana SM, Parmar D. Clinical Management of Head and Neck Cancer Cases: Role of Pharmacogenetics of CYP2 and GSTs. Oncol Res Treat. 2016;39(4):221-6.

35. Xu N, Wu Y-P, Ke Z-B, Liang Y-C, Cai H, Su W-T, Tao X, Chen S-H, Zheng Q-S, Wei Y, et al: Identification of key DNA methylation-driven genes in prostate adenocarcinoma: an integrative analysis of TCGA methylation data. Journal of Translational Medicine 2019, 17(1).

36. Yilmaz L, Borazan E, Aytekin T, Baskonus I, Aytekin A, Oztuzcu S, Bozdag Z, Balik A. Increased UGT1A3 and UGT1A7 Expression is Associated with Pancreatic Cancer. Asian Pac J Cancer Prev. 2015;16(4):1651-5.

37. Cengiz B, Yumrutas O, Bozgeyik E, Borazan E, Igci YZ, Bozgeyik I, Oztuzcu S. Differential expression of the UGT1A family of genes in stomach cancer tissues. Tumor Biology. 2015;36(8):5831-7.

38. Chen W, Fu W, Deng Q, Li Y, Wang K, Bai Y, Wu X, Li G, Wang G, Huang J, et al. Multiple metals exposure and chromosome damage: Exploring the mediation effects of microRNAs and their potentials in lung carcinogenesis. Environ Int. 2019;122:291-300.

39. Dong XT, Liu YD. Expression and significance of miR-24 and miR-101 in patients with advanced gastric cancer. Oncol Lett. 2018;16(5):5769-74.

40. Jin FF, Yang R, Wei Y, Wang D, Zhu YN, Wang XH, Lu YS, Wang YB, Zen K, Li LM. HIF-1alpha-induced miR-23a approximately 27 a approximately 24 cluster promotes colorectal cancer progression via reprogramming metabolism. Cancer Lett. 2019;440-441:211-22.

41. Jing PY, Zhao N, Xie NL, Ye MX, Zhang Y, Zhang ZP, Li MY, Lai XF, Zhang J, Gu ZP: miR-24-3p/FGFR3 Signaling as a Novel Axis Is Involved in Epithelial-Mesenchymal Transition and Regulates Lung Adenocarcinoma Progression. J Immunol Res 2018, 2018:2834109.

42. Lang B, Shang C, Meng LR. Targeted Silencing of S100A8 Gene by miR-24 to Increase Chemotherapy Sensitivity of Endometrial Carcinoma Cells to Paclitaxel. Med Sci Monit. 2016;22:1953-8.

\section{Figures}




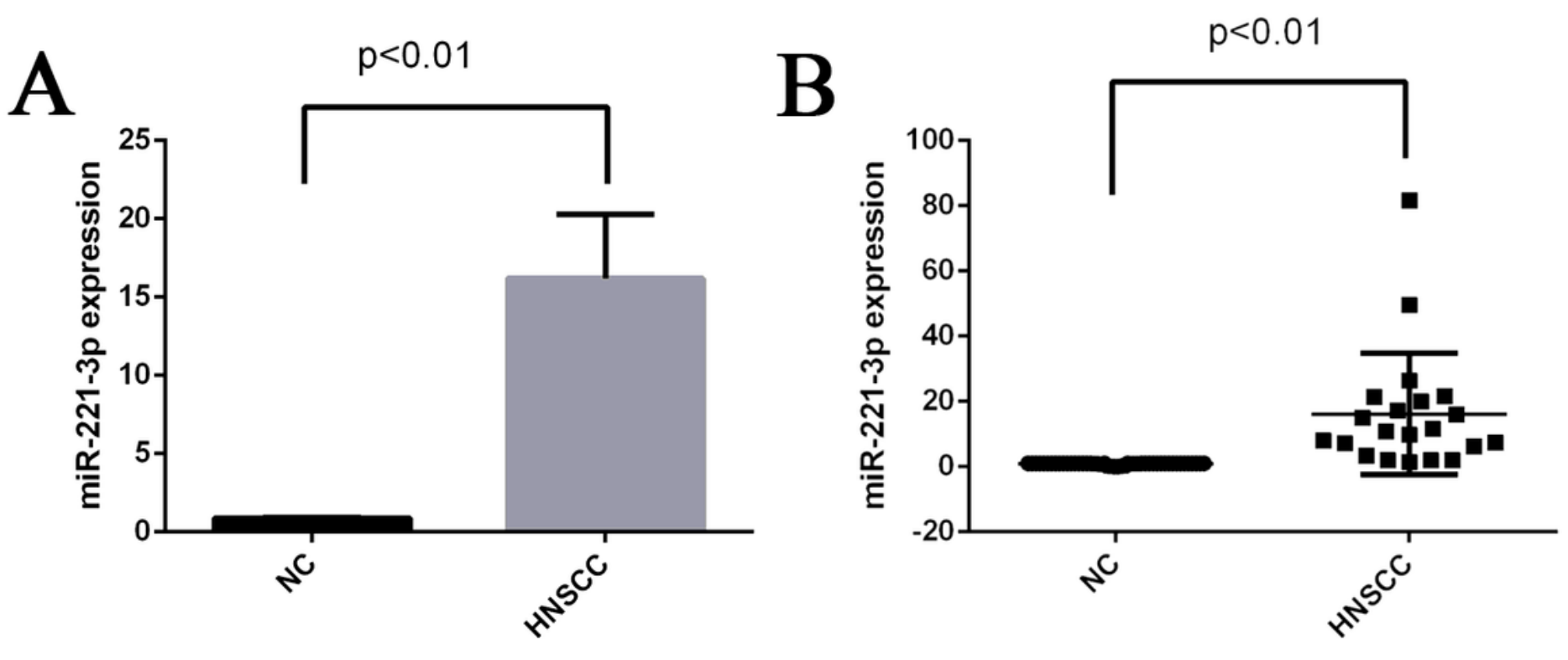

Figure 1

MiR-221-3p levels in HNSCC and NC tissue specimens. RT-qPCR was used to detect miR-221-3p was significantly up-regulated in the tumor tissues of an HNSCC cohort $(n=48)$ relative to control tissues $(n=$ 21) $\triangle \mathrm{P} \otimes 0.01)$.

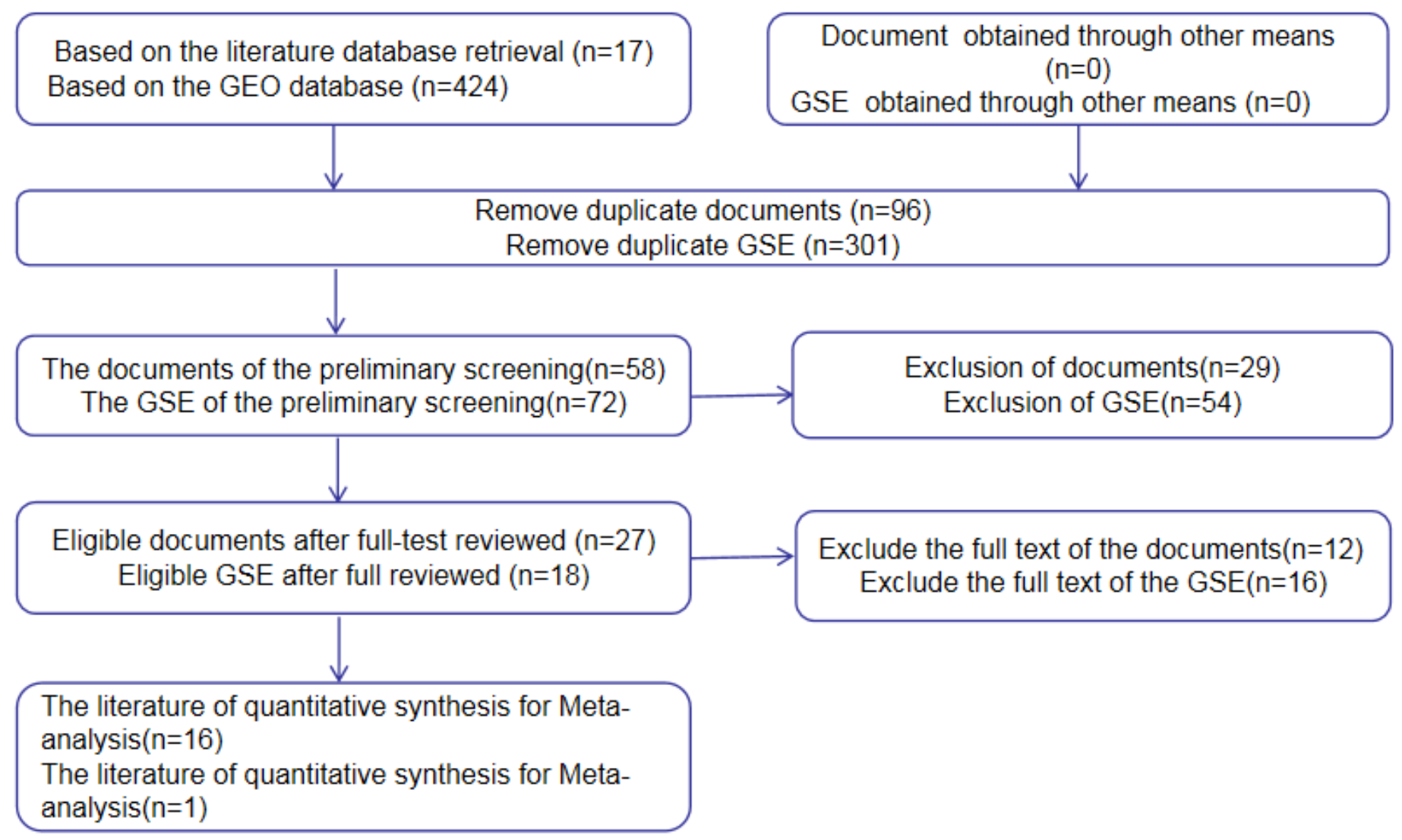


Figure 2

The flow chart of literature search and selection of relevant studies. sixteen out of 424 GEO microarray datasets met our inclusion criteria. At the same time, a total of 17 articles were retrieved from the initial search, and one papers (Zhou Cheng. et al) were selected after the full-text review based on the inclusion criteria.

A

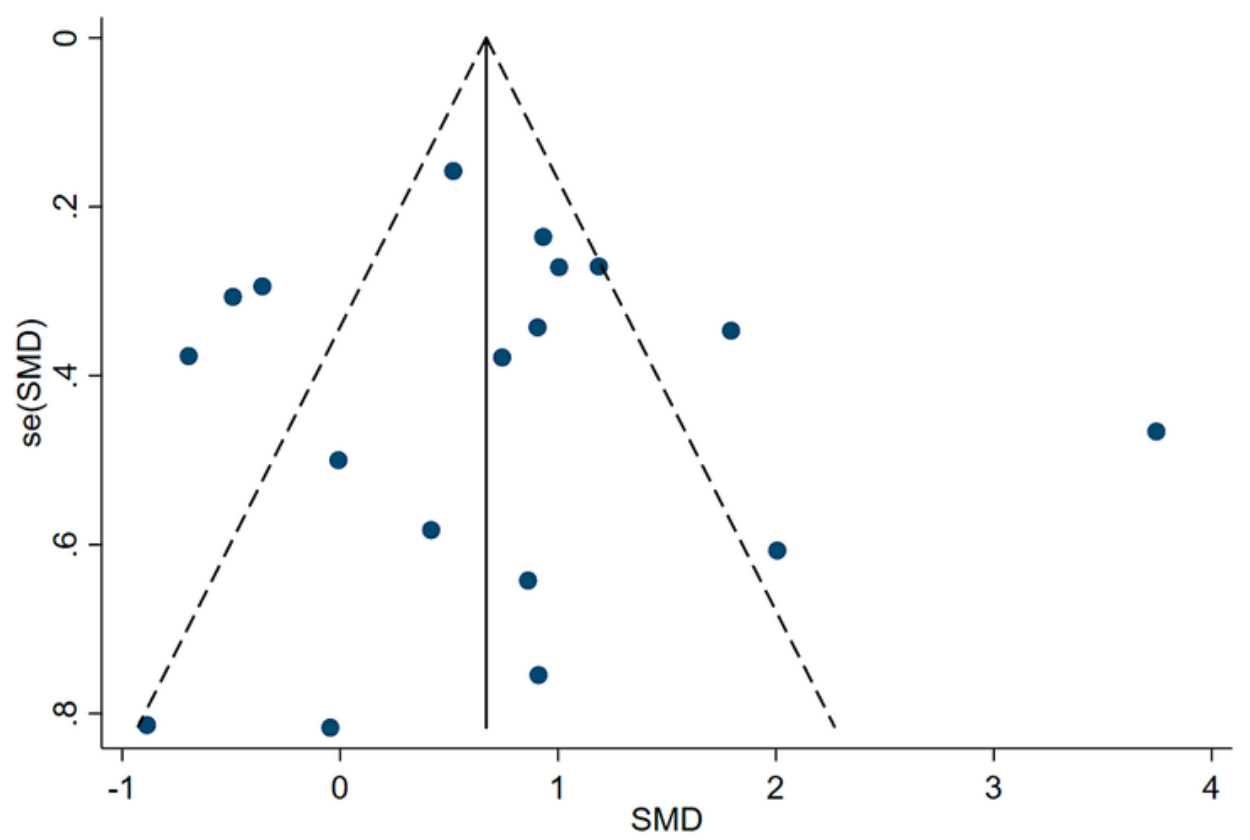

\section{B}

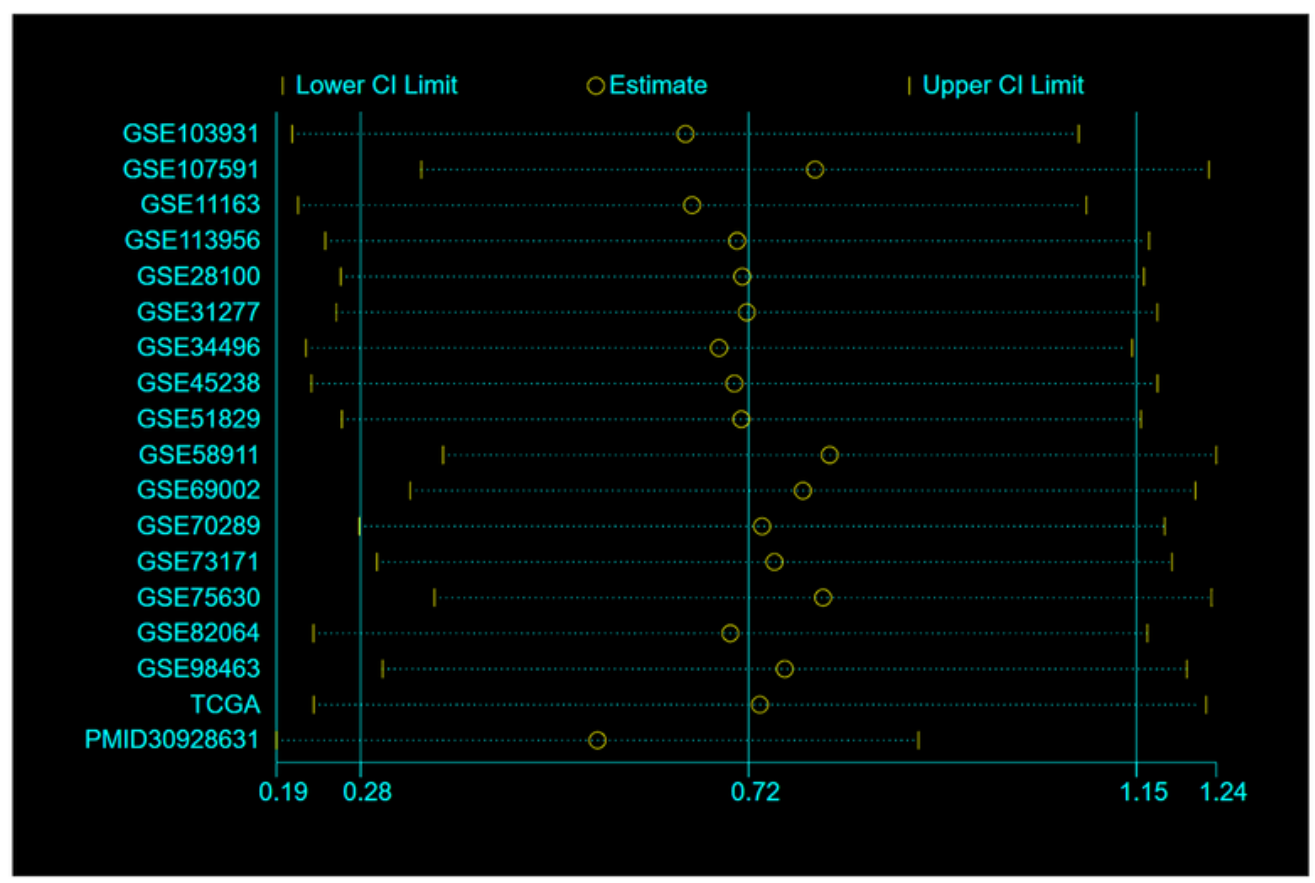

Figure 3 
Bias analysis. (A) Funnel plots of published data bias for meta-analysis of miR-21. (B) Sensitivity analysis for meta-analysis of miR-221-3p.

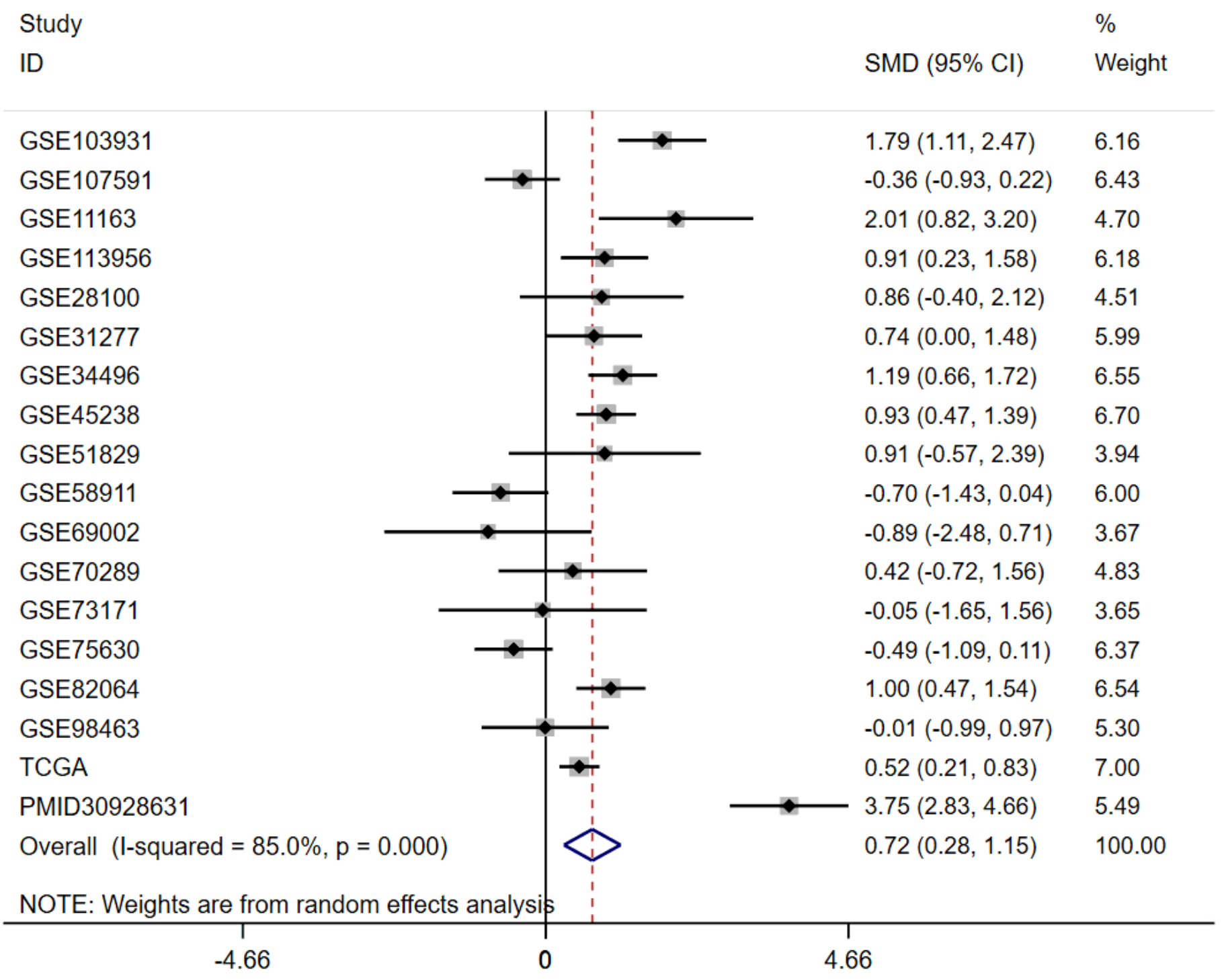

\section{Figure 4}

Forest plots. The combined SMD of miR-221-3p expression levels in HNSCC samples was $0.717(95 \% \mathrm{Cl}$ $: 0.283,1.152)$. 

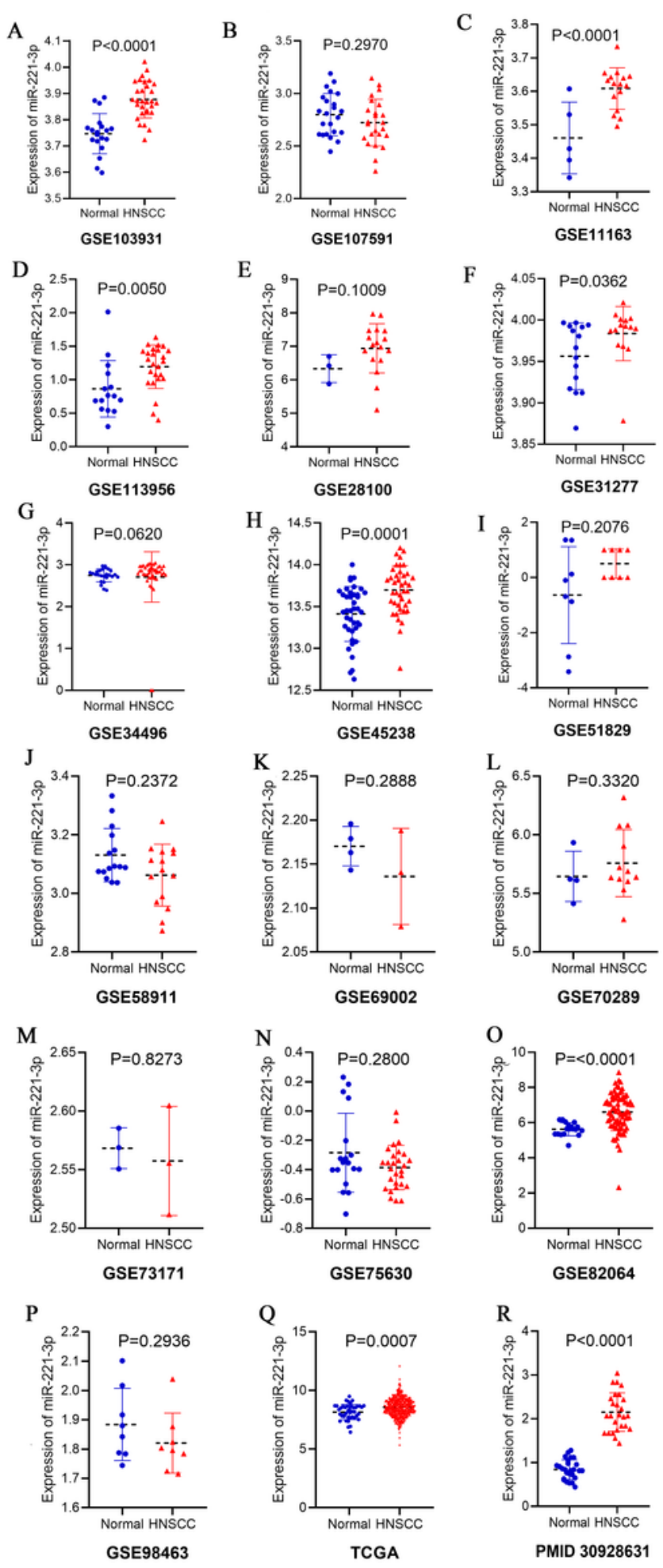

\section{Figure 5}

The expression data of miR-221-3p in HNSCC from TCGA, each included GEO and the literature. 

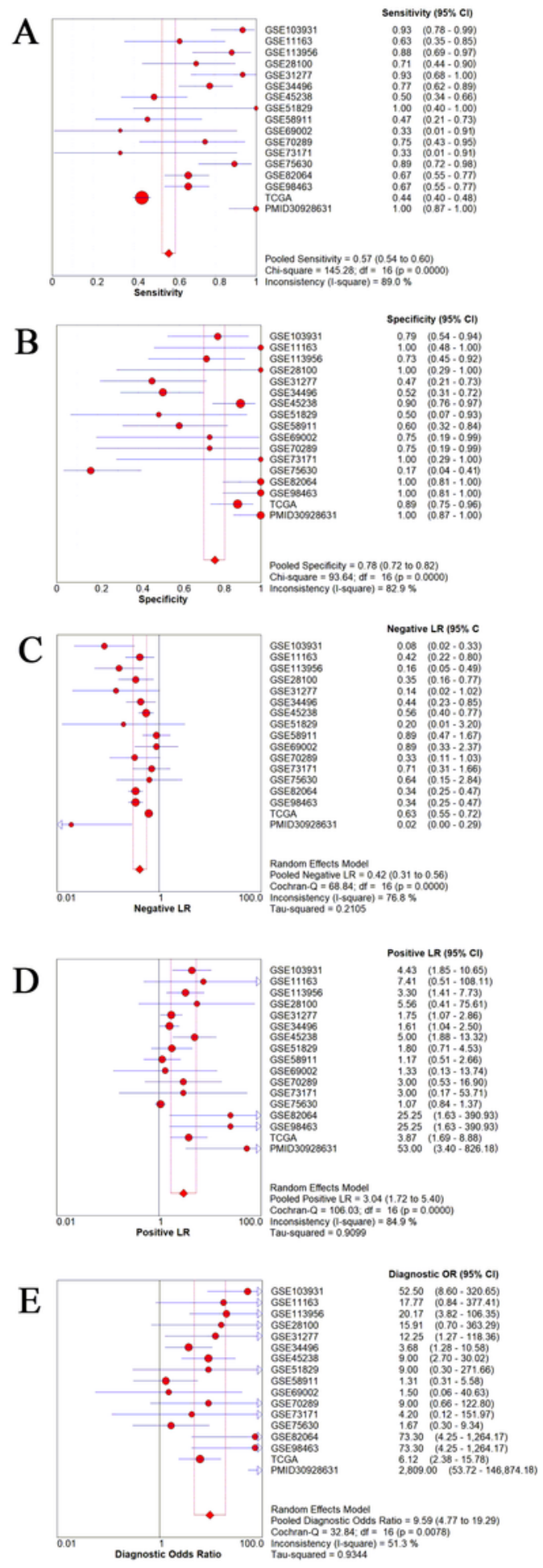

\section{Figure 6}

The diagnostic value of miR-221-3p in HNSCC. (A) sensitivity; (B) specificity; (C) PLR;(D) NL; and (E) diagnostic odds ratio. 
A

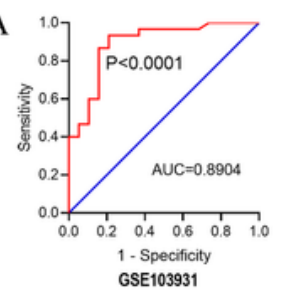

D

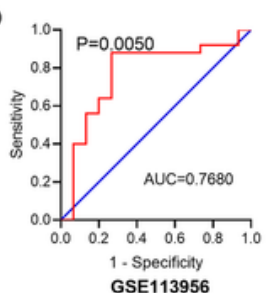

G

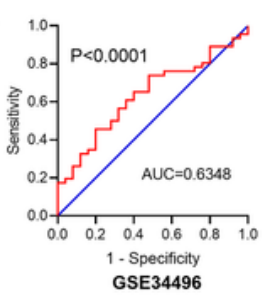

J

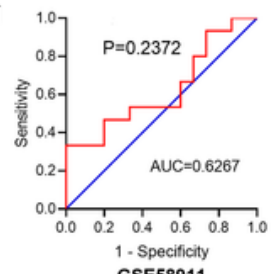

M
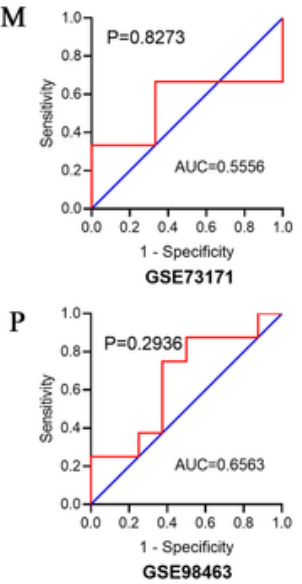

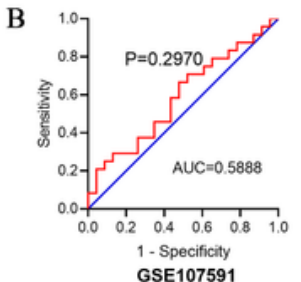

E

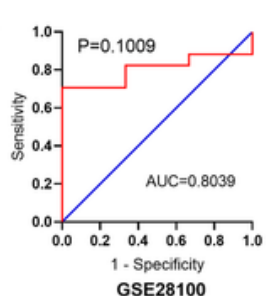

$\mathrm{H}$

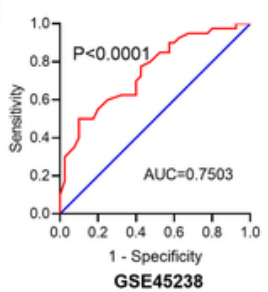

K
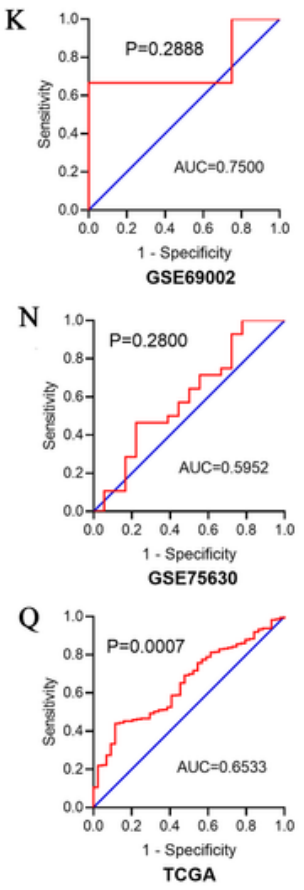

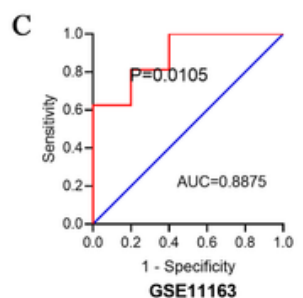

F

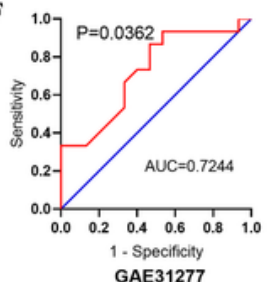

I
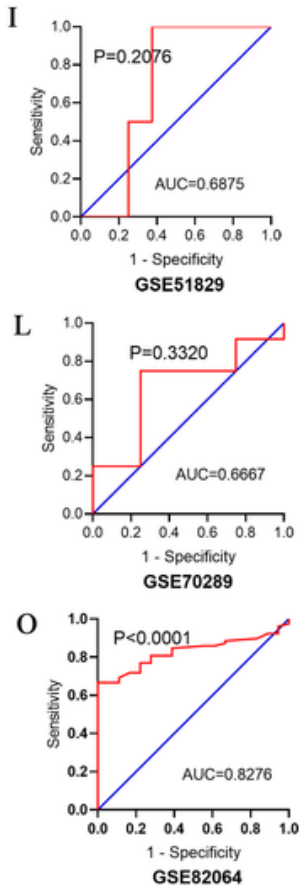

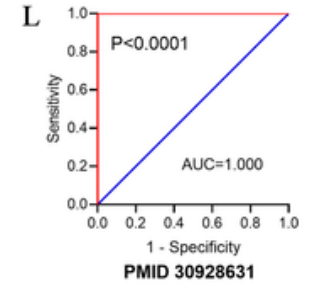

\section{Figure 7}

Receiver operating characteristic (ROC) curves showing the diagnostic value of miR-221-3p in HNSCC. 


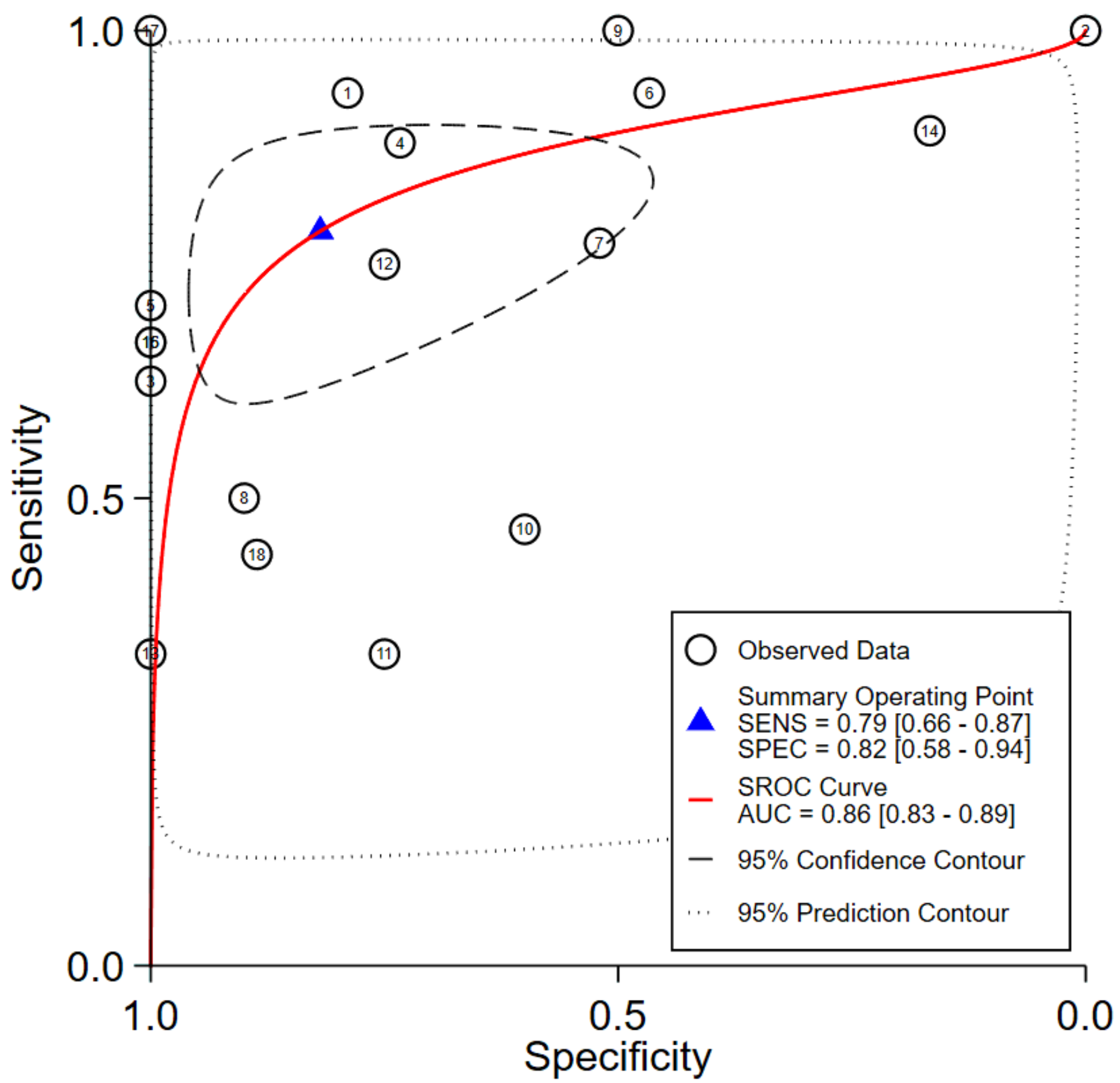

Figure 8

Summary ROC (SROC) curve showing the diagnostic performance of miR-221-3p in HNSCC. The sROC curve AUC was 0.86 (95\% Cl: 0.83-0.89), indicating high predictive power. 


\section{MiRWalk}

5311

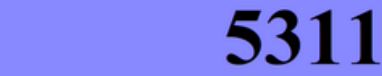

Figure 9

Venn diagram showing overlapping miR-221-3p target genes.

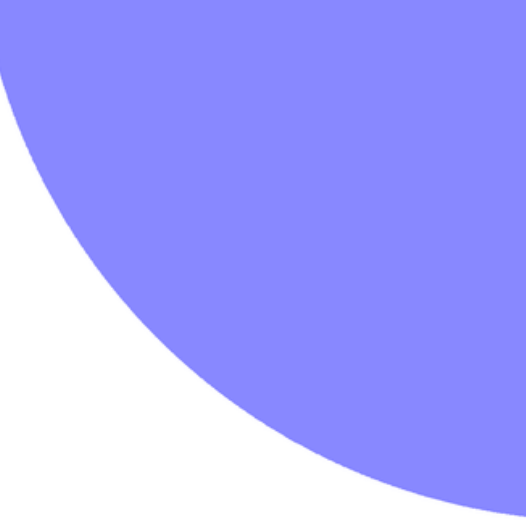

\section{GEPIA}

\section{7
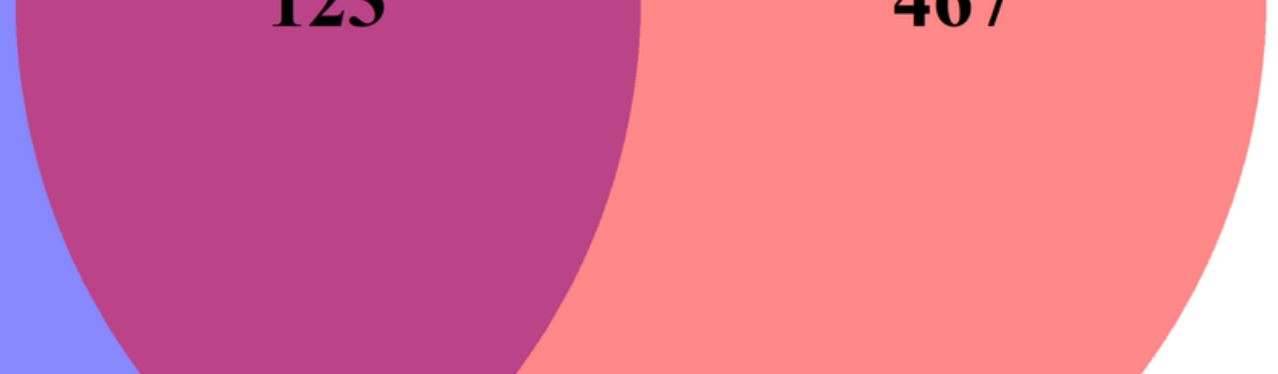


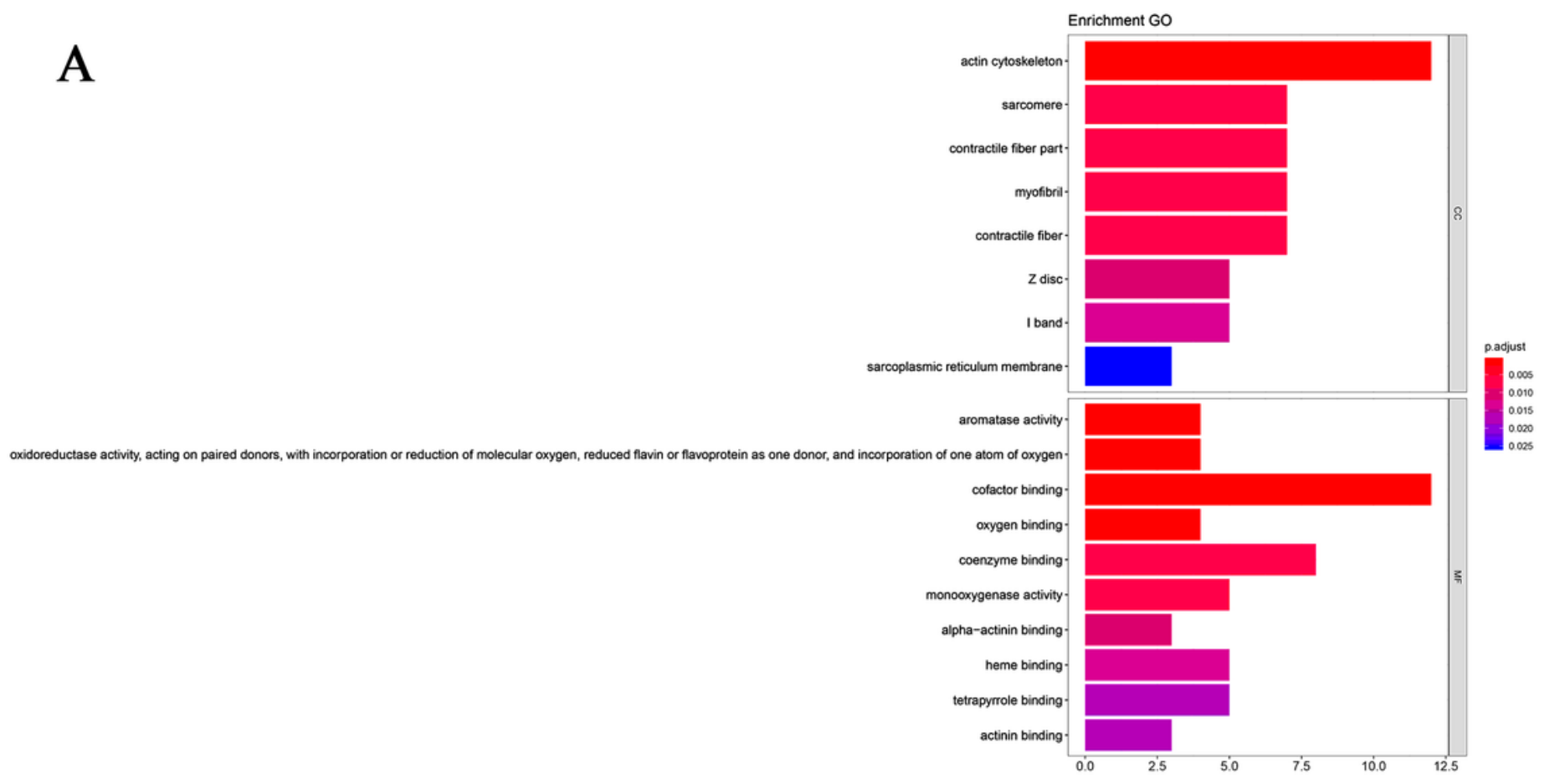

B

KEGG pathway

Drug metabolism - cytochrome P450-

Metabolism of xenobiotics by cytochrome P450 Retinol metabolism -
Chemical carcinogenesis -
Tyrosine metabolism -
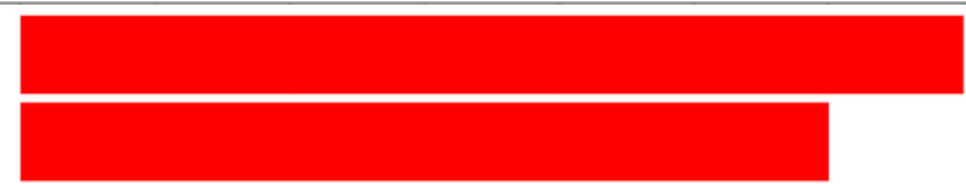

p.adjust
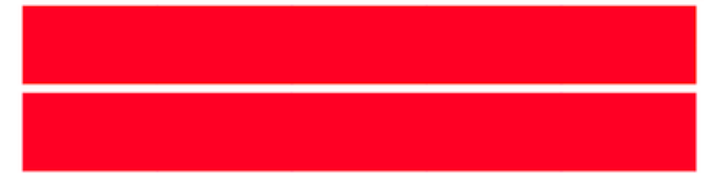

Figure 10

Enrichment analysis of GO and KEGG pathways of miR-221-3p target genes. A. Gene ontology (GO) of candidate genes; B. Kyoto Encyclopedia of Genes and Genomes (KEGG) analysis. 


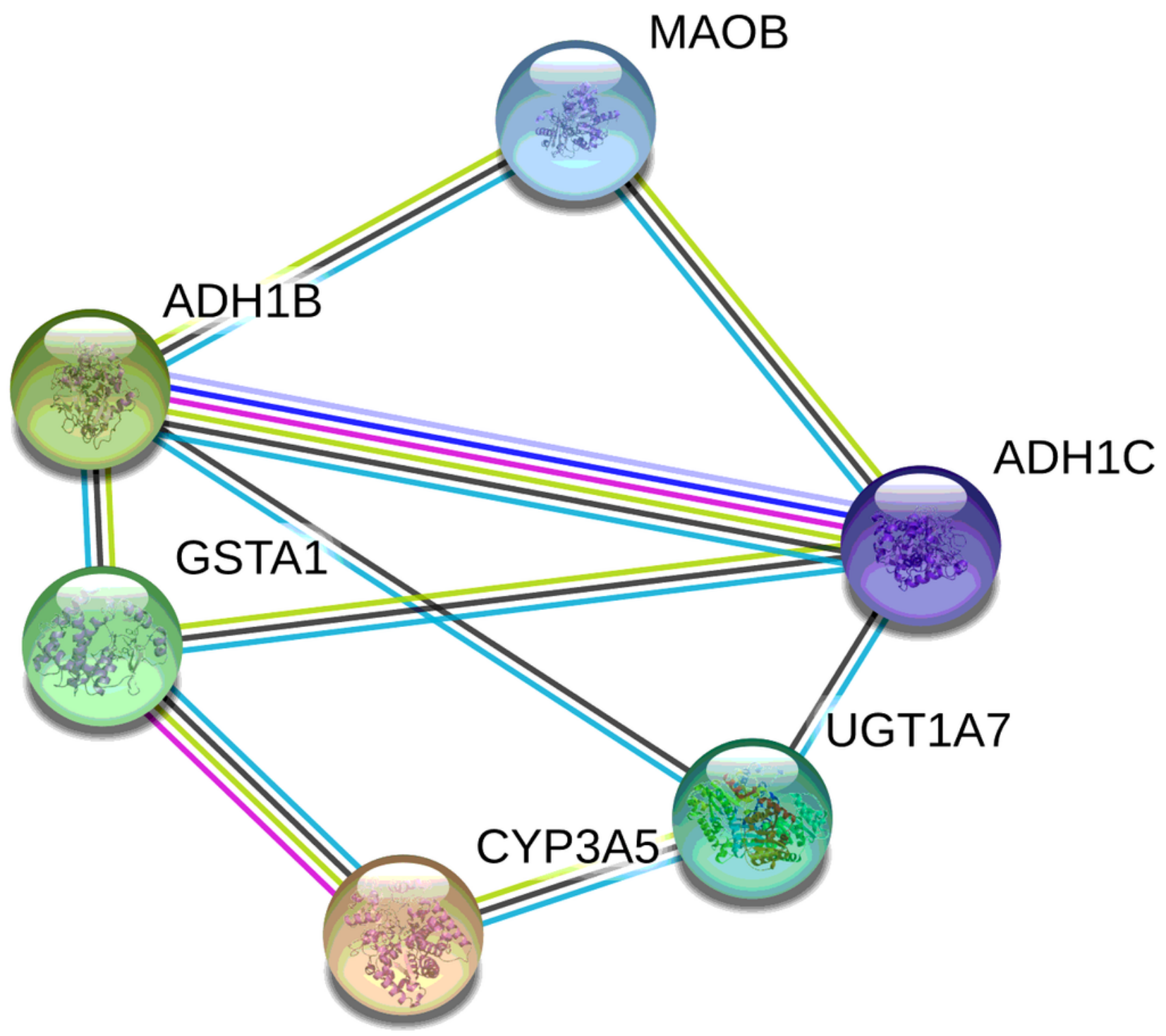

Figure 11

PPI network. The nodes represent target genes and the lines are associations between genes, which showing the connections among the 7 miR-221-3p targets associated with the Drug metabolism cytochrome P450 pathway. 


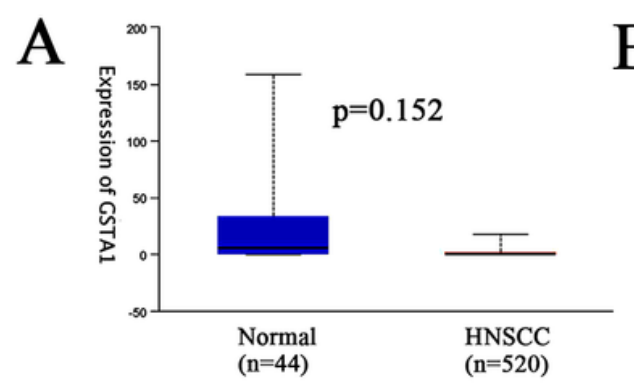

B
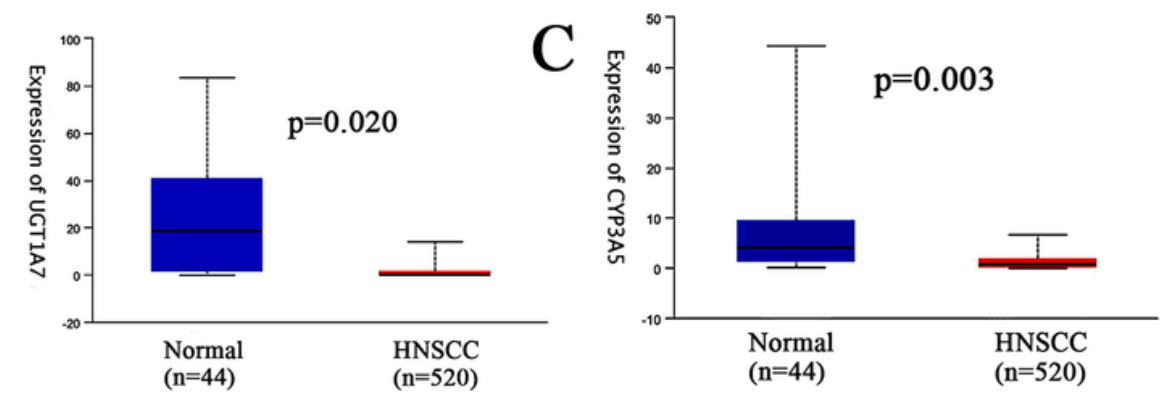

D

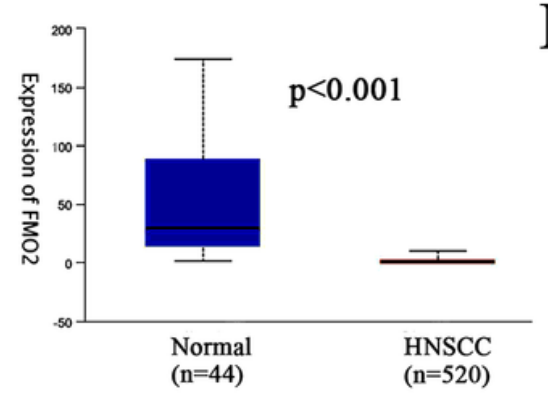

E
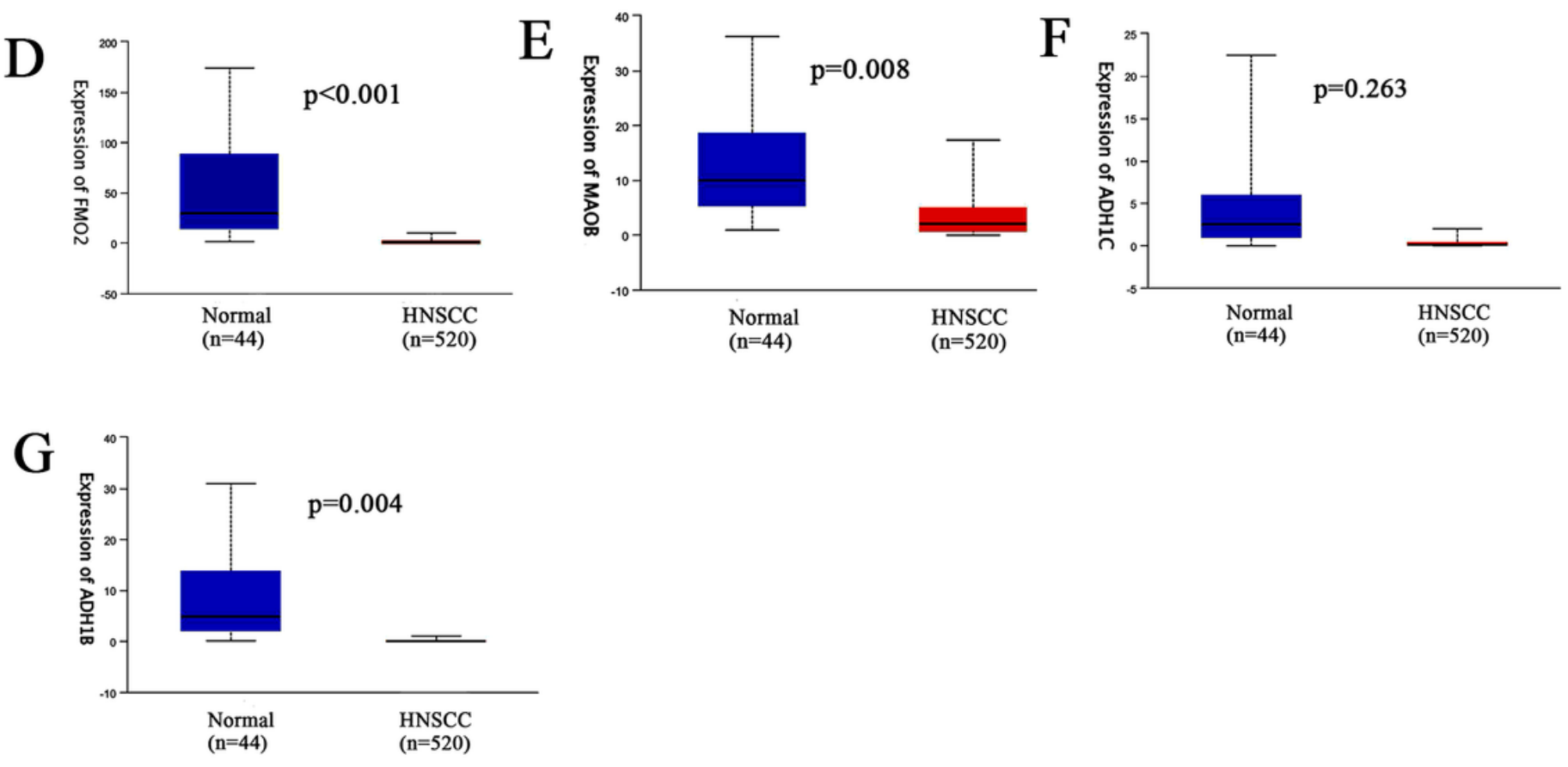

Figure 12

The expression levels of miR-221-3p target genes in HNSCC.A-G pictures represents the expression of the following genes: GSTA1, UGT1A7, CYP3A5, FMO2, MAOB, ADH1C, ADH1B. 

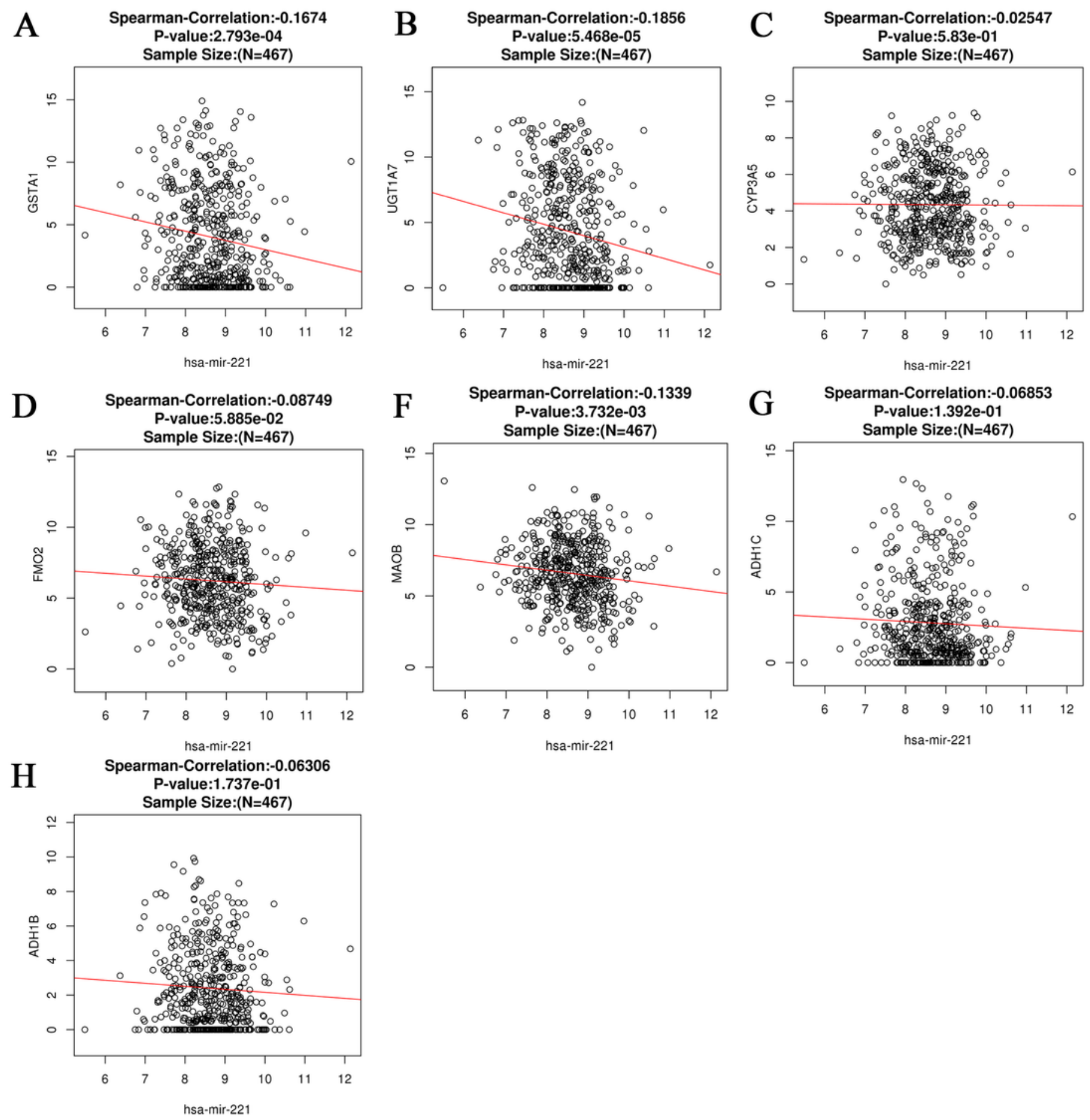

\section{Figure 13}

Spearman analysis. A-G show the association between miR-221-3p expression levels and the 7 identified target genes involved in the Drug metabolism - cytochrome P450 pathway. 